Revista de Derecho

de la Pontificia Universidad Católica de Valparaíso

XXXV (Valparaíso, Chile, 2010, 20 Semestre)

[pp. $361-406]$

\title{
LIBERTAD DE ESTABLECIMIENTO DE FARMACIAS EN LA UNIÓN EUROPEA
}

["Freedom of Establishment of Pharmacies in the European Union"]

\author{
Juan Francisco Pérez Gálvez* \\ Universidad de Almería, España
}

\begin{abstract}
RESUMEN
El Tribunal de Justicia de la Unión Europea ha decretado que la reserva de la titularidad y la explotación de las farmacias a los farmacéuticos no vulnera el derecho de establecimiento, ni la libre circulación de capitales. También declara lícita la limitación en el número de autorizaciones para establecer farmacias en virtud de módulos poblacionales y distancias mínimas, e impide privilegiar en el proceso de selección a los farmacéuticos autóctonos. Dicho de otro modo, no es posible en la Unión Europea discriminar a los farmacéuticos por razón de nacionalidad, o por condiciones que tienen que ver con el desarrollo del ejercicio profesional en una determinada zona geográfica.

Palabras Clave: Libertad de establecimiento en la Unión Europea - Ordenación farmacéutica - Salud pública - Discriminación por razón de nacionalidad.
\end{abstract}

\begin{abstract}
The Court of Justice of the European Union has decreed that the restriction of ownership and operation of pharmacies by pharmacists does not infringe the right of establishment or the free circulation of capital. The Court has also declared lawful the limitation of the number of authorizations to establish pharmacies by virtue of population modules and minimum distances, preventing local pharmacists from being privileged in the selection process. In other words, it is not possible that pharmacists are discriminated in the European Union due to nationality or for reasons related to the professional performance in a certain geographical zone.

KEYWORDS: Freedom of establishment in the European Union - Pharmaceutical Organization - Public Health - Discrimination due to nationality.
\end{abstract}

* Catedrático de Derecho Administrativo de la Facultad de Derecho de la Universidad de Almería, España. Dirección postal: Avenida Federico García Lorca, No 92, 5A, 04005 Almería, España. Correo electrónico: jperezg@ual.es 


\section{EL ESTABLECIMIENTO DE FARMACIAS: UNA CONTROVERSIA}

\section{RECURRENTE}

\section{Unión Europea.}

La regulación del régimen jurídico de las farmacias en la Unión Europea presenta diferencias notables. Sintetizando y simplificando, debo aludir a la existencia de dos modelos o tipologías fundamentales. Aquellos países que consagran en su ordenamiento jurídico la reserva de la propiedad de las farmacias a favor de los farmacéuticos. Dichos Estados son: Austria, Bulgaria, Chipre, Dinamarca, Finlandia, Francia, Alemania, Grecia, Italia, Letonia, Luxemburgo, Eslovenia y España (13 de 27). Los que condicionan la apertura de farmacias a una ordenación farmacéutica predeterminada, y por tanto, a unos requisitos de índole demográfica y/o geográfica: Austria, Bélgica, Dinamarca, Estonia, Finlandia, Francia, Grecia, Italia, Letonia, Luxemburgo, Malta, Portugal, Eslovenia, España y Reino Unido (15 de 27) ${ }^{1}$.

Desde el año 2006 hasta nuestros días, se ha intensificado la controversia jurídica en la Unión Europea, en especial lo relativo al libre establecimiento de farmacias. No sólo afecta a la reserva de titularidad a farmacéuticos o a la planificación territorial de estos establecimientos en base a criterios demográficos o geográficos. Subyacen importantes intereses económicos con numerosos actores: el propio colectivo de farmacéuticos, laboratorios, distribuidores, superficies comerciales, gobiernos implicados ${ }^{2}$ y por supuesto a los ciudadanos que son los destinatarios de este servicio, que debe prestarse en las mejores condiciones de calidad y precio por unidad dispensada.

La Comisión Europea, en su afán liberalizador puso en práctica la Directiva $\mathrm{N}^{\circ}$ 2006/123/CE del Parlamento Europeo y del Consejo, de 12 de diciembre de 2006, relativa a los servicios en el mercado interior (DOUE ${ }^{\circ}$ L 376, de 27 de diciembre de 2006), denominada coloquialmente "Directiva Bolkestein" (hace referencia al entonces comisario encargado del mercado interior europeo). Esta disposición no puede aplicarse al ámbito de los ser-

\footnotetext{
${ }^{1}$ Véase: Consejo General de Colegios Oficiales de Farmacéuticos, Informe: Modelos de farmacia en la Unión Europea, (diciembre de 2007).

${ }^{2}$ Véase la sentencia del Tribunal de Justicia de las Comunidades Europeas (Gran Sala) de 19 de mayo de 2009, apartado 57: "[...] el consumo excesivo y la utilización incorrecta de medicamentos suponen un derroche de recursos financieros, que resulta tanto más perjudicial cuando que el sector farmacéutico genera costes considerables y debe responder a necesidades crecientes, mientras que los recursos financieros que pueden destinarse a la asistencia sanitaria no son ilimitados, cualquiera que sea el modo de financiación [...]. A este respecto, procede señalar que existe una relación directa entre dichos recursos financieros y los beneficios de los operadores económicos activos en el sector farmacéutico, dado que, en la mayoria de los Estados miembros, las entidades encargadas del seguro de enfermedad asumen la financiación de los medicamentos prescritos".
} 
vicios sanitarios. Su preámbulo, considerando 22, determina: "La exclusión de los servicios sanitarios del ámbito de aplicación de la presente Directiva debe abarcar los servicios sanitarios y farmacéuticos prestados por profesionales de la salud a los pacientes con objeto de evaluar, mantener o restaurar su estado de salud cuando estas actividades están reservadas a profesiones reguladas en el Estado miembro en que se preste el servicio". El artículo 2.2.f) de la Directiva excluye "los servicios sanitarios, prestados o no en establecimientos sanitarios, independientemente de su modo de organización y de financiación a escala nacional y de su carácter público o privado".

Sin embargo, su artículo 15, exige a los Estados miembros un examen de la existencia de trabas específicas: límites cuantitativos y territoriales y, concretamente, límites fijados en función de la población o de una distancia geográfica mínima entre prestadores.

En este contexto, la Comisión Europea ha propugnado una política liberalizadora en materia de establecimiento de farmacias que se ha materializado en la incoación de distintos procedimientos por incumplimientos abiertos contra varios Estados miembros: "En los últimos tres años los esfuerzos por liberalizar lo más posible el sector de las oficinas de farmacia se han concretado en varios procedimientos administrativos por incumplimiento, algunos de los cuales han acabado ante el Tribunal de Justicia. Se trata de una estrategia que la Comisión Europea ha desarrollado hasta 2008, cuando mostraba su intención de continuar los procedimientos por incumplimiento a través de la Dirección General de Mercado Interior y Servicios en distintos ámbitos del mercado interior, citando expresamente los relativos a la movilidad de los pacientes y el reembolso de los costes médicos, el establecimiento de farmacias, etc. Al mismo tiempo la Comisión Europea se ha propuesto perseguir las violaciones más groseras del artículo 43 del Tratado CE, que consagra el derecho de establecimiento, y del artículo 49 del Tratado CE, relativo a la libre prestación de servicios, en relación con los servicios de salud y lo que la Comisión denomina 'las discriminaciones patentes en el sector de las farmacias"'3.

${ }^{3}$ Véase: ORdoñez Solís, David, La regulación española de las oficinas de farmacia en el contexto del mercado único a la luz de la jurisprudencia europea", en Gaceta Jurídica de la Unión Europea y de la Competencia, 10 (2009), p. 19. 
Estos Estados han sido: Italia ${ }^{4}$, Austria $^{5}$, Alemania $^{6}$, Portugal $^{7}$ y España ${ }^{8}$. En ningún caso se ha decretado por la jurisprudencia que el régimen jurídico vigente fuese contrario al Derecho comunitario?.

El Tribunal de Justicia (Gran Sala) de la Unión Europea, con fecha 1 de junio de 2010, acaba de pronunciarse sobre el régimen jurídico de la ordenación farmacéutica y la libertad de establecimiento en la Unión Europea. Sin duda se trata de una sentencia de alcance, que condiciona la efectividad del derecho de establecimiento, en un sector tan sensible, como el de las farmacias. A su estudio, análisis, y consecuencias, dedico los siguientes epígrafes.

${ }^{4}$ Véase: Comisión Europea, IP/06/858, Bruselas, 28 de junio de 2006. El procedimiento por incumplimiento lo interpuso la Comisión Europea ante el Tribunal de Justicia el 22 de diciembre de 2006. A juicio de la Comisión las normas italianas relativas a las farmacias son incompatibles con la libertad de establecimiento (artículo $43 \mathrm{CE}$ ) y la libre circulación de capitales (artículo $56 \mathrm{CE}$ ). Véase la sentencia del Tribunal de Justicia de las Comunidades Europeas (Gran Sala) de 19 de mayo de 2009.

${ }^{5}$ Véase: Comisión Europea, IP/06/858, Bruselas, 28 de junio de 2006. En términos similares al caso de Italia, la Comisión Europea adoptó en junio de 2006 un dictamen motivado contra Austria al apreciar la incompatibilidad de las restricciones legislativas relativas a las farmacias con la libertad de establecimiento garantizada por el artículo 43 del Tratado CE.

${ }^{6}$ Véase: Comisión Europea, IP/08/1352, Bruselas, 18 de septiembre de 2008. En este caso, en septiembre de 2008, seguía en la fase administrativa del procedimiento por incumplimiento y la Comisión Europea ya había emitido su dictamen motivado en el que cuestionaba la conformidad con el Derecho comunitario del régimen de propiedad de las farmacias. A juicio de la Comisión, Alemania debe derogar la prohibición para los no farmacéuticos de poseer una farmacia y la prohibición dirigida a los farmacéuticos de poseer más de cuatro farmacias (una principal y tres sucursales). Asimismo, la Comisión Europea impugna ante el Tribunal de Justicia la legislación alemana que impone una proximidad entre la farmacia principal y sus sucursales. Se trata de medidas incompatibles con la libertad de establecimiento y no pueden ser justificadas por razones vinculadas a la protección de la salud.

${ }^{7}$ Véase: Comisión Europea, IP/08/1352, Bruselas, 18 de septiembre de 2008. Para la Comisión Europea no es admisible desde el punto de vista del Derecho comunitario que la legislación portuguesa prohíba a las empresas comercializadoras de medicamentos poseer o gestionar farmacias; asimismo, la legislación portuguesa prohíbe la posesión de más de cuatro farmacias. Se trata, a juicio de la comisión Europea, de exigencias desproporcionadas respecto de la necesidad de garantizar la protección de la salud y tampoco son compatibles con la libertad de establecimiento.

${ }^{8}$ Véase: Comisión Europea, IP/06/858, Bruselas, 28 de junio de 2006. La Comisión Europea hace girar su dictamen motivado en torno al carácter restrictivo de la normativa de planificación territorial y a la prohibición de la acumulación de farmacias.

${ }^{9}$ Véase: Razluin Lizarraga, José Antonio, La reserva de la propiedad y la titulariza de las oficinas de farmacia a los farmacéuticos no es contraria al Derecho comunitario europeo, en Actualidad Jurídica Aranzadi, 777 (2009), pp. 7-11. 


\section{España.}

El sistema farmacéutico español es bueno: "España cuenta con la tercera mejor ratio europea en cuanto a número de farmacias por número de habitantes. En concreto, contamos con una botica por cada 2.143 habitantes, proporción sólo mejorada por Grecia y Bélgica. [...]. En nuestro país existen un total de 2.149 municipios con una población inferior a los 1.000 habitantes, y de los 1.114 municipios con menos de 500 habitantes, sólo 36 carecen de botica. [...]. El 99\% de la población de España tiene una oficina de farmacia en el municipio en que habita" 10 , ha estado y está intervenido ${ }^{11}$, y a lo largo del tiempo se ha puesto de manifiesto que adolece de rigideces que le impiden adaptarse a las necesidades actuales ${ }^{12}$.

Es por ello que las sucesivas reformas legislativas efectuadas en los últimos quince años han dado lugar a cuatro tipos de modificaciones, a saber: en primer lugar, la modificación de la organización territorial de las oficinas de

${ }^{10}$ Véase: Contestación del Ministerio de Sanidad y Consumo al Dictamen Motivado de la Comisión Europea, de 24 de agosto de 2006.

${ }^{11}$ Para justificar una afirmación tan contundente, véase: Nieto, Alejandro, La Ley alemana de Farmacia de 28 de agosto de 1960, en Revista de Administración Pública, 35 (1961), pp. 361: "No es un azar que durante siglos haya existido o exista en todos los países civilizados una fuerte intervención administrativa sobre farmacias y boticarios. Un Estado liberal puede abstenerse de intervenir y controlar el comercio de mercaderías ordinarias; nunca dejará de hacerlo en las farmacias, ya que la salud pública está en juego. El producto farmacéutico es tan importante como la actividad del médico: es su complemento. La existencia del uno sin la otra es inimaginable. Y por lo mismo que el ejercicio de la medicina ha estado y estará siempre estrechamente controlado por la Administración, también ha de estarlo la farmacéutica. No se trata solamente (aunque ya fuera por sí solo bastante) de que haya medicinas peligrosas, cuyo tráfico debe regularse, o que el uso indebido o imprudente de la mayoría pueda ser perjudicial, si no aparece rodeado de las mayores garantías. La realidad es que fuera del mundo de la farmacopea hay numerosas substancias peligrosas y aun mortales: el presunto suicida no precisa necesariamente del recurso al veronal para quitarse la vida mientras haya azoteas elevadas, cuya utilización a tales fines nunca podrá evitarse; como tampoco es la morfina el único vicio que perjudica al organismo. Lo que caracteriza la especialidad farmacéutica no es la peligrosidad potencial de sus productos, sino el que esta peligrosidad forme parte de su propia naturaleza y destino. Esto tiene de común con la industria de las armas de fuego: puede matarse con veronal o con un raticida, con un martillo o con una pistola, pero siempre estará libre el tráfico de raticidas o martillos y regulado el de pistolas y veronal, porque la peligrosidad de éstas es directa, radica en su misma esencia y fin, mientras que la de aquéllas es únicamente potencial, como desviación de su uso primario".

${ }^{12}$ Véase: TJUE. Petición de decisión prejudicial presentada por el Juzgado Contencioso-Administrativo de Granada el 18 de diciembre de 2008 - "Carlos Sáez Sánchez y Patricia Rueda Vargas/Junta de Andalucía y Manuel Jalón Morente y otros”, partes codemandadas (C-563/08)- (DOUE N ${ }^{\circ}$ C 69, de 21 de marzo de 2009, p. 21). 
farmacia para garantizar la atención farmacéutica a todos los ciudadanos; en segundo lugar, se ha modificado el procedimiento de autorización, siempre bajo los principios de concurrencia competitiva, transparencia, mérito, capacidad y procedimiento reglado; en tercer lugar, la obligación de la presencia de un farmacéutico en la dispensación, como condición y requisito inexcusable para dar un servicio de calidad; en cuarto lugar, la flexibilidad en la prestación horario del servicio, con el compromiso de su mantenimiento, el carácter de mínimos de los horarios oficiales y la audiencia de los interesados para garantizar el servicio.

Los efectos perseguidos han sido, de una parte que aumentara la implantación de farmacias, mejorando sensiblemente la distribución de estos establecimientos en las zonas de la periferia urbana propias del extrarradio de las ciudades, en las que los distintos sistemas de módulos de población para abrir una nueva farmacia lo imposibilitaban al computarlos como núcleos municipales; de otra mejorar el régimen de prestación del servicio al permitir la libertad horaria a la que me he referido anteriormente.

También se han requerido notables esfuerzos del sistema educativo para adecuar el número de titulados que producen las universidades españolas a las verdaderas necesidades sociales. España es el país de la Unión Europea en el que se encuentra más del 20 por ciento de los estudiantes de farmacia.

La Ley $N^{\circ} 16 / 1997$, de 25 de abril, de regulación de servicios de las oficinas de farmacia (BOE. de 26 de abril, núm. 100), pretendía mejorar la atención farmacéutica a la población mediante las siguientes medidas: regulación de la definición y funciones de las oficinas de farmacia; fijar nuevos módulos de población, sin perjuicio de las regulaciones autonómicas a las que posteriormente me referiré; adecuación del procedimiento de autorización de apertura a la Ley $\mathrm{N}^{\circ} 30 / 1992$, de 26 de noviembre, de régimen jurídico de las Administraciones públicas y del procedimiento administrativo común, cuya competencia corresponde a las Comunidades Autónomas; regulación de la transmisión de las oficinas de farmacia; exigencia de la presencia constante de un farmacéutico en la actividad de dispensación y flexibilización del régimen de jornada y horario de apertura de estos establecimientos.

El artículo 2 de la Ley No 16/1997, de 25 de abril, dispone: "1. [...] al objeto de ordenar la asistencia farmacéutica a la población, las Comunidades Autónomas, a las que corresponde garantizar dicha asistencia, establecerán criterios especificos de planificación para la autorización de oficinas de farmacia. [...]./ 2. La planificación de oficinas de farmacia se establecerá teniendo en cuenta la densidad demográfica, caracteristicas geográficas y dispersión de la población, con vistas a garantizar la accesibilidad y calidad en el servicio, y la suficiencia en el abastecimiento de medicamentos, según las necesidades sanitarias en cada territorio./La ordenación territorial de estos establecimientos se efectuará por 
módulos de población y distancias entre oficinas de farmacia, que determinarán las Comunidades Autónomas, conforme a los criterios generales antes señalados. En todo caso, las normas de ordenación territorial deberán garantizar la adecuada atención farmacéutica a toda la población./ 3. El módulo de población minimo para la apertura de oficinas de farmacia será, con carácter general, de 2.800 habitantes por establecimiento. Las Comunidades Autónomas, en función de la concentración de la población, podrán establecer módulos de población superiores, con un limite de 4.000 habitantes por oficina de farmacia. En todo caso, una vez superadas estas proporciones, podrá establecerse un a nueva oficina de farmacia por fracción superior a 2.000 habitantes./ No obstante lo dispuesto en el párrafo anterior, las Comunidades Autónomas podrán establecer módulos de población inferiores para las zonas rurales, turisticas, de montaña, o aquéllas en las que, en función de sus características geográficas, demográficas o sanitarias, no fuese posible la atención farmacéutica aplicando los criterios generales./ 4. La distancia minima entre oficinas de farmacia, teniendo en cuenta criterios geográficos y de dispersión de la población será, con carácter general, de 250 metros. Las Comunidades Autónomas, en función de la concentración de la población, podrán autorizar distancias menores entre las mismas; asimismo, las Comunidades Autónomas podrán establecer limitaciones a la instalación de oficinas de farmacia en la proximidad de los centros sanitarios".

La planificación y ordenación territorial de estos establecimientos en base a los módulos de población y distancias mínimas entre oficinas de farmacia son cuestiones sobre los que habré de pronunciarme en este trabajo, a tenor de lo establecido en la sentencia del Tribunal de Justicia de la Unión Europea (Gran Sala) de 1 de junio de 2010.

Esta regulación normativa contraviene los sucesivos intentos de liberalización de farmacias que diversas entidades, desde el Tribunal de Defensa de la Competencia de España ${ }^{13}$ hasta las asociaciones pro libre apertura de oficinas de farmacia, han mantenido a los largo de los últimos veinte años. Sus argumentos se pueden sintetizar del siguiente modo: los sectores sin competencia imponen las condiciones a los consumidores; sin competencia ni moderan sus precios, ni mejoran la calidad y no cuidan el trato al cliente; no es verdad que liberalizar un mercado suponga desregularlo, pues muchas veces, la liberalización de un sector exige la elaboración de una regulación más profusa y minuciosa que la existente en situación de monopolio; las funciones del farmacéutico tradicional las asumen hoy día los laboratorios farmacéuticos, con ello se acentúa el carácter comercial y mercantil de estos

${ }^{13}$ Véase: Tribunal de Defensa de la Competencia, La competencia en España: balance y nuevas propuestas (Madrid, 1995), pp. 229-271. 
establecimientos ${ }^{14}$; el sistema actual supone un coste elevado, tanto para los ciudadanos como para las finanzas públicas; el derecho a la protección de la salud y el deber de promoverla (artículos 43, 50 y 51 de la Constitución Española), implica que para defender los intereses públicos deban estar fuertemente reguladas las actividades de producción y distribución de medicamentos, pero no ampara elementos claramente restrictivos de la competencia, generadores de ineficiencias, que no son necesarios para la defensa de esos intereses públicos que se dice proteger.

Una planificación no restrictiva beneficiaría conceptos tales, como: derecho al trabajo (libre ejercicio profesional), libertad de empresa en el marco de una economía de mercado, derecho a la asistencia sanitaria de toda la población independientemente del número de habitantes, igualdad de los ciudadanos ante la ley, redistribución de renta y riqueza, dinamización de la economía, creación de empleo directo e indirecto, etc.

En nuestros días sigue habiendo dificultades para dar cobertura farmacéutica a toda la población, hay una demanda social parcial de cambio en el modelo farmacéutico por parte de un nutrido grupo de profesionales sin farmacia y las tendencias liberalizadoras en otros países, así como el régimen precios, descuentos y exportaciones paralelas ${ }^{15}$ evidencian que hay lagunas por colmar.

Un buen ejemplo del componente económico y de los equilibrios para mantener la rentabilidad financiera del sector -tan comentado y denostado-

${ }^{14}$ Si la ley sanciona expresamente la ausencia del farmacéutico, es porque se reconoce la realidad de la farmacia sigue funcionando en ausencia de éste. La imagen tradicional del farmacéutico elaborando preparados en la rebotica ya no existe. ¿Cuál es el papel del farmacéutico en el sistema sanitario hoy? ¿Por qué funciona la farmacia sin su presencia? El hecho es que la actividad rutinaria se reduce a la venta del medicamento y a una gestión de las existencias del almacén. El farmacéutico, si su ética profesional es algo relajada, ni aparece por la farmacia. De este modo, el papel del profesional de la farmacia está desapareciendo como consecuencia de la anulación de la competencia y, por tanto, de la exigencia de continua formación y atención al servicio que en cualquier otra profesión son ineludibles. La conclusión parece inminente, la desregulación al introducir competencia, inducirá la atención obligada del farmacéutico y, a largo plazo, contribuirá a redefinir su papel en la cadena sanitaria. Sin embargo, lo que se pretende en la actualidad es reforzar notablemente el papel de este profesional en el ámbito de la salud.

${ }^{15}$ Véase el dictamen del Comité Económico y Social Europeo sobre la Comunicación de la Comisión al Consejo, al Parlamento Europeo, al Comité Económico y Social y al Comité de las Regiones, Una industria farmacéutica europea más fuerte en beneficio del paciente. Un llamamiento para la acción [COM (2003) 383 final] (DOUE No C 241, de 28 de septiembre de 2004, pp. 7-14). Comunicación de la Comisión relativa a las importaciones paralelas de especialidades farmacéuticas cuya comercialización ya ha sido autorizada, COM (2003), 839 final. 
se visualiza especialmente en la actividad de las exportaciones paralelas. Se trata de un mecanismo de compensación del mercado previsto para equiparar los precios de los medicamentos entre unos países y otros, y sobre todo, para mantener los márgenes empresariales.

Las condiciones para la existencia de las exportaciones paralelas se pueden resumir en las siguientes: el medicamento debe estar registrado en los dos países, ya que si no se da esta circunstancia se trataría de una exportación normal; la diferencia de precios debe ser importante, ya que en caso contrario no interesaría efectuar el envío y distribución, aparte de otros trámites obligados como la adaptación de la información; el medicamento debe tener el mismo nombre o muy similar en ambos países y su presentación también; el medicamento debe haber superado su periodo de vigencia de la patente del producto, ya que mientras tanto, el propietario puede impedir su comercialización por terceros no autorizados; este tipo de comercio, sólo lo llevan a cabo mayoristas autorizados para esta función.

El negocio estriba en que un almacén en España adquiere unidades de un determinado medicamento y las vende a otro almacén de otro país, con un margen muy superior al habitual. El almacén de este país receptor, todavía compra estas unidades muy por debajo del precio en su país, y también obtiene un margen mayor, que en parte repercute en sus clientes e incluso puede llegar al consumidor final. El medicamento es exactamente el mismo, pero es necesario añadirle la información en el idioma del país, lo que normalmente se resuelve introduciendo la hoja de instrucciones traducida. Además, para cerrar el círculo de las garantías sanitarias, los países que reciben el comercio paralelo han establecido un registro especial para estos medicamentos, en los que se controlan los lotes y los certificados de análisis evitando cualquier falsificación. En caso de una hipotética retirada en el país de origen, esta puede efectuarse también en el país de destino. Los medicamentos son manipulados externamente por los distribuidores, pero no se permite ninguna manipulación que afecte al interior del envase. De este modo, los países con precios más bajos se convierten en exportadores, mientras que los de precios más altos o de precio libre, son los importadores.

España se ha convertido en uno de los exportadores paralelos más importantes, ya que su nivel de precios es de los más bajos, junto con el de Portugal y Grecia. La cuantía real del comercio paralelo desde España a otros países de la Unión Europea, se estima en el 10-15 \% de nuestro mercado interior. Las cooperativas y almacenes obtienen importantes porcentajes de beneficio, que sirven para enjugar pérdidas en muchos casos o mantener el nivel de competencia en descuentos que ofrecen a las farmacias. Si hubiera que buscar las causas últimas de que exista este tipo de exportación, y no haya sido posible llegar a un consenso dentro de la Unión Europea para un mercado único de 
los medicamentos, podríamos resumirlas en dos: primera, la persistencia de diferentes sistemas de fijación de precios por parte de los gobiernos; segunda, la oposición de las propias multinacionales para establecer control de precios en aquellos países donde el precio es libre o el beneficio se controla para el conjunto de la empresa. Acabar con el comercio paralelo llevaría implícito acordar entre los Estados miembros de la Unión, un sistema uniforme de fijación de precios. En la actualidad se observa una aproximación gradual de precios en los nuevos medicamentos, con diferencias que hacen poco apetecibles las exportaciones paralelas.

Pocos farmacéuticos saben que su margen actual, mermado tras la rebaja impuesta por el Gobierno, puede verse nuevamente afectado, si se reduce o impide el comercio paralelo. Su cooperativa o almacén distribuidor hacen lo que pueden para seguir exportando y conseguir mantener los retornos o el margen de intermediación en los límites actuales. Algunos incluso, han podido mantener los márgenes anteriores a la reducción, gracias a las exportaciones paralelas y, desde luego, la salud económica de la distribución está ligada en parte a esta actividad, aunque nadie quiere reconocerlo, para no ser víctima de restricciones.

\section{Sentencia del Tribunal de Justicia (Gran Sala) DE 1 DE JUNIO DE 2010: LITIGIO ORIGINARIO, CUESTIONES PREJUDICIALES Y LA ADMISIBILIDAD DE LAS PETICIONES DE DECISIÓN PREJUDICIAL}

La Comunidad Autónoma de Asturias aprobó el Decreto $N^{\circ} 72 / 2001$, de 19 de julio, regulador de las oficinas de farmacia y botiquines en el Principado de Asturias (BOPA. de 28 de julio, núm. 175), origen de la Sentencia del Tribunal de Justicia de la Unión Europea (Gran Sala), de 1 de junio de 2010.

El artículo primero, apartado primero, párrafo primero de dicho decreto dispone la ordenación administrativa de las "zonas farmacéuticas": "El territorio de la Comunidad Autónoma se ordena en zonas farmacéuticas, las cuales coincidirán con carácter general, con las zonas básicas de salud establecidas en la planificación sanitaria del Principado de Asturias" ${ }^{16}$.

El artículo segundo establece los módulos de población para adscribir una oficina de farmacia: "1. En cada zona farmacéutica el número de oficinas de farmacia corresponderá al módulo de 2.800 habitantes por oficina de farma-

${ }^{16}$ Tal y como figura en la propia Sentencia, apartado 11, la Comunidad Autónoma de Asturias se divide: en 68 zonas básicas de salud, que coinciden, con carácter general, con las zonas farmacéuticas. 
cia. Una vez superada esta proporción podrá establecerse una nueva oficina de farmacia por la fracción superior a 2.000 habitantes./ 2. En todas las zonas básicas de salud y en todos los concejos podrá existir al menos una oficina de farmacia"17.

Respecto a la distancia mínima, el artículo cuarto determina: "1. La distancia minima entre los locales de oficinas de farmacia será, con carácter general, de 250 metros, independientemente de la zona farmacéutica a la que pertenezcan./ 2. Esta distancia minima de 250 metros deberá ser guardada igualmente en relación con los centros sanitarios de cualquier zona farmacéutica, ya sean éstos públicos o privados concertados de asistencia extrahospitalaria u hospitalaria, con consultas externas o dotados de servicios de urgencia, estén los mismos en funcionamiento o en fase de construcción./ Este requisito de distancia a los centros sanitarios no será de aplicación en las zonas farmacéuticas con una única oficina de farmacia ni en las localidades que, contando actualmente con una única oficina de farmacia, no sea previsible, dadas sus caracteristicas, la apertura de nuevas oficinas de farmacia. [...]".

Respecto al procedimiento para la concesión de autorizaciones de apertura, la propia sentencia en los apartados 16 a 18 lo resume de modo necesario y providencial, para contestar los argumentos de los demandantes ${ }^{18}$.

El Decreto $\mathrm{N}^{\circ} 72 / 2001$, de 19 de julio, establece en un anexo, un baremo de méritos que contiene los criterios sobre la base de los cuales se evaluará a los candidatos que hayan presentado una solicitud para obtener la titularidad de una nueva farmacia, en función de su formación, su experiencia profesional y su experiencia académica.

Como singularidades con incidencia en este comentario jurispruden-

${ }^{17}$ El Decreto $\mathrm{N}^{\circ} 72 / 2001$, de 19 de julio, regulador de las oficinas de farmacia y botiquines en el Principado de Asturias, en su artículo 3 precisa: " $A$ los efectos de este Decreto, el cómputo de la población se hará sobre la base de los datos derivados de la última revisión del padrón municipal".

${ }^{18}$ Véase: STJUE (Gran Sala) de 1 de junio de 2010, apartados 16-18, donde resume los artículos 6 a 17 del Decreto $N^{\circ} 72 / 2001:$ 16. "Con arreglo a estos artículos, la Comunidad Autónoma de Asturias tiene la obligación de organizar, de oficio, como minimo una vez al año, el procedimiento para la concesión de autorizaciones de establecimiento de nuevas farmacias con objeto de tener en cuenta la evolución de la densidad demográfica". 17. "En la convocatoria del concurso deberá constar la zona farmacéutica y, en su caso, el concejo y la localidad, donde procede la instalación. Tras la publicación de la convocatoria, los farmacéuticos interesados presentarán sus solicitudes. Y los documentos que certifiquen sus méritos. A continuación, se reunirá una comisión compuesta por miembros de la Administración, del colegio oficial de la profesión y de las asociaciones profesionales para evaluar los méritos de los candidatos". 18. "Una vez concedida la autorización, el farmacéutico adjudicatario tiene la obligación de designar el local en el que ejercerá su actividad. Las autoridades competentes verificarán que se respetan los criterios de planificación territorial establecidos por la normativa". 
cial, debo destacar los puntos 4, 6 y 7 de dicho anexo, pues sustentan parte de la controversia jurídica: "4. No será valorada la experiencia profesional como ejercicio de farmacéutico titular o cotitular en una oficina de farmacia ni cualquier otra clase de méritos cuando una u otros hubieran servido con anterioridad para obtener una autorización de instalación. [...]./ 6. Los méritos profesionales referidos al ejercicio profesional obtenidos en el ámbito del Principado de Asturias se computarán con un incremento del 20\%./ 7. En caso de empate al aplicar el baremo, las autorizaciones se otorgarán de acuerdo con el siguiente orden de prioridad:/ a) Farmacéuticos que no hayan sido titulares de oficinas de farmacia./ b) Farmacéuticos que hayan sido titulares de oficinas de farmacia en zonas farmacéuticas o municipios de población inferior a 2.800 habitantes./ c) Farmacéuticos que hayan desempeñado su ejercicio profesional en el ámbito del Principado de Asturias. [...]".

El litigio originario tiene su origen cronológico en el año 2002. La Comunidad Autónoma de Asturias decidió iniciar un procedimiento para la concesión de autorizaciones de instalación de nuevas farmacias, con arreglo a los artículos 6 a 17 del Decreto $N^{\circ} 72 / 2001$, de 19 de julio. Las normas de concurso establecían la apertura de 24 nuevas farmacias en función, en particular, de la densidad demográfica, la dispersión de la población, la distancia entre las farmacias y los grupos mínimos de población.

El Tribunal Superior de Justicia de Asturias presenta petición de decisión prejudicial el 24 de diciembre de 2007, en el proceso contencioso administrativo “José Manuel Blanco Pérez/Consejería de Salud y Servicios Sanitarios del Principado de Asturias, Federación Empresarial de Farmacéuticos Españoles y Plataforma para la Libre Apertura de Farmacias" (C-570/07) y el 27 de diciembre de 2007 en el asunto "María del Pilar Chao Gómez/ Principado de Asturias y Celso Fernández Gómez" (C-571/07) (DOUE, de 29 de marzo de 2008, núm. C 79, pp. 13 y 14). Por auto del Tribunal de Justicia de 28 de febrero de 2008 se acumularon ambos procedimientos, a efectos de las fases escrita y oral, así como de la sentencia.

Los demandantes, con el título de farmacéuticos, deseaban abrir una nueva farmacia en la Comunidad Autónoma de Asturias sin que se les aplicase el régimen de planificación territorial establecido en el Decreto $\mathrm{N}^{\circ}$ $72 / 2001$, de 19 de julio ${ }^{19}$.

${ }^{19}$ Los demandantes interpusieron un recurso contra la Resolución de 14 de junio de 2001, de la Consejería de Salud y Servicios Sociales, por la que se convocaba un concurso para la autorización de oficinas de farmacia en el Principado de Asturias, así como contra la Resolución del Consejo de Gobierno del Principado de Asturias, de 10 de octubre de 2002, que confirmaba la Resolución anterior. También interpusieron un recurso ante el Tribunal Superior de Justicia de Asturias mediante el que impugnaban la resolución presunta relativa la reclamación presentada contra el Decreto $\mathrm{N}^{\circ}$ 
Cuestionaron la conformidad a Derecho de las resoluciones adoptadas por las autoridades de la Comunidad Autónoma y del Decreto $\mathrm{N}^{\circ} 72 / 2001$, de 19 de julio, alegando en particular, que éstos impiden el acceso de los farmacéuticos a las nuevas farmacias en la Comunidad Autónoma de Asturias. Además consideran que dicho Decreto establecía criterios inadmisibles para la selección de los titulares de nuevas farmacias.

En este contexto, el Tribunal Superior de Justicia de Asturias decidió suspender el procedimiento y plantear al Tribunal de Justicia la cuestión prejudicial cuestionando si el régimen establecido en el Decreto $\mathrm{N}^{\circ} 72 / 2001$, de 19 de julio, constituye una restricción de la libertad de establecimiento incompatible con el artículo $49^{20}$ del Tratado de 13 de diciembre de 2007, sobre el Funcionamiento de la Unión Europea, en adelante TFUE. Más en concreto, en el asunto C-570/07, pregunta literalmente si: " ¿El artículo (49 TFUE) es opuesto a lo establecido en los artículos 2, 3 y 4 del Decreto $N^{\circ} 72 / 2001$, asi como en los apartados 4, 6 y 7 del Anexo del mencionado Decreto?"21. En el asunto C-571/07, el Tribunal Superior de Justicia de Asturias planteó: “¿El artículo (49 TFUE) es contrario a la regulación que se contiene en la legislación de la Comunidad Autónoma [...] de Asturias en relación con la autorización de instalación de Oficinas de Farmacia?"22.

Particular interés presenta la solicitud de oposición a la admisibilidad de las peticiones de la decisión prejudicial planteadas por el Consejo general de Colegios Oficiales de Farmacéuticos de España, así como distintos gobiernos europeos, a saber: España, Grecia, Francia e Italia.

Sobre esta cuestión, el Tribunal determina con rotundidad:

i) Cuando las cuestiones planteadas se refieren a la interpretación del

72/2001, de 19 de julio, y, en particular, sus artículos 2, 4, 6 y 10, así como su anexo relativo al baremo de méritos.

${ }^{20}$ Véase: Tratado de 13 de diciembre de 2007 [Tratado sobre el Funcionamiento de la Unión Europea. Para la redacción de este trabajo, utilizo la versión consolidada subsiguiente al "Tratado de Lisboa", de 13 de diciembre 2007) (DOUE núm. 83, de 30 de marzo 2010)], artículo 49: "En el marco de las disposiciones siguientes, quedarán prohibidas las restricciones a la libertad de establecimiento de los nacionales de un Estado miembro en el territorio de otro Estado miembro. Dich a probibición se extenderá igualmente a las restricciones relativas a la apertura de agencias, sucursales of filiales por los nacionales de un Estado miembro establecidos en el territorio de otro Estado miembro./ La libertad de establecimiento comprenderá el acceso a las actividades no asalariadas y su ejercicio, asi como la constitución y gestión de empresas y, especialmente, de sociedades, tal como se definen en el párrafo segundo del artículo 54, en las condiciones fijadas por la legislación del pais de establecimiento para sus propios nacionales, sin perjuicio de las disposiciones del capitulo relativo a los capitales".

${ }^{21}$ Véase la sentencia del Tribunal de Justicia (Gran Sala), de 1 de junio de 2010, apartado 30.

${ }^{22}$ Ibíd., apartado 31. 
Derecho de la Unión, el Tribunal de Justicia, esta obligado a pronunciarse: "A este respecto, espreciso recordar que corresponde exclusivamente a los órganos jurisdiccionales nacionales que conocen del litigio y que han de asumir la responsabilidad de la decisión judicial que debe adoptarse apreciar, a la luz de las particularidades de cada asunto, tanto la necesidad de una decisión prejudicial para poder dictar sentencia, como la pertinencia de las cuestiones que plantean al Tribunal de Justicia. Por consiguiente, cuando las cuestiones planteadas se refieren a la interpretación del Derecho de la Unión, el Tribunal de Justicia está, en principio, obligado a pronunciarse [...]"23.

ii) Las cuestiones relativas al Derecho de la Unión gozan de una presunción de pertinencia: "Así, la negativa del Tribunal de Justicia a pronunciarse sobre una cuestión planteada por un órgano jurisdiccional nacional sólo es posible cuando resulta evidente que la interpretación solicitada del Derecho de la Unión no tiene relación alguna con la realidad o con el objeto del litigio principal, cuando el problema es de naturaleza hipotética o también cuando el Tribunal de Justicia no dispone de los elementos de hecho y de Derecho necesarios para responder de manera útil a las cuestiones planteadas [...]"24.

En virtud de la jurisprudencia del TJUE, el Alto Tribunal determinó que "en las resoluciones de remisión, el órgano jurisdiccional nacional motivó su resolución sobre la necesidad de plantear las cuestiones prejudiciales indicando que la conformidad a Derecho de la normativa controvertida en los asuntos principales depende de la interpretación que el Tribunal de Justicia realice del artículo 49 TFUE"25. También señaló que no resulta evidente que la interpretación solicitada no tuviese relación alguna con la realidad o con el objeto de los litigios principales ni que el problema sea de naturaleza hipotética. Pero sobre todo destaca que la peculiaridad de que se trate de un asunto estrictamente nacional no implica que no pueda darse en supuestos que guardan relación con los intercambios intracomunitarios ${ }^{26}$.

${ }^{23}$ Ibíd., apartado 35.

${ }^{24}$ Ibíd., apartado 36.

${ }^{25}$ Ibíd., apartado 37.

${ }^{26}$ Véase: STJUE (Gran Sala) de 1 de junio de 2010, apartado 39: “Ciertamente, consta que los demandantes en los asuntos principales son de nacionalidad española y que todos los elementos de ambos litigios principales se circunscriben al interior de un único Estado miembro. Sin embargo, según reiterada jurisprudencia, la respuesta del Tribunal de Justicia puede ser útil para el órgano jurisdiccional remitente incluso en tales circunstancias, en particular en el supuesto de que el Derecho nacional le obligue a conceder a un español los mismos derechos que el Derecho de la Unión reconoce a un nacional de un Estado miembro distinto del Reino de España que se halle en la misma situación [...]"; apartado 40: "Además, si bien una normativa nacional como la controvertida en el litigio principal-que es indistintamente aplicable a los nacionales españoles y a los nacionales de los demás Estados miembros- sólo puede, por lo general, estar comprendida en el ámbito 
Respecto a las insuficiencias alegadas por los opositores a la admisibilidad de las peticiones de decisión prejudicial, relativas a la descripción del marco jurídico y fáctico y al alcance de las cuestiones planteadas, el Tribunal las desestima entendiendo que no concurren en el asunto enjuiciado.

\section{PRIMER PRoblema QUE Aborda la SENTENCIA:}

\section{RESTRICCIÓN A LA LIBERTAD DE ESTABLECIMIENTO DE FARMACIAS}

\section{El Derecho de la Unión no merma la competencia de los Estados miembros} para ordenar y organizar sus servicios sanitarios.

a) Bases y régimen jurídico de la salud pública en la Unión Europea y en España. El Tratado de 13 de diciembre de 2007, sobre el funcionamiento de la Unión Europea [Versión consolidada subsiguiente al “Tratado de Lisboa" de 13 de diciembre de 2007) (DOUE núm. 83, de 30 de marzo 2010)], artículo 168 (antiguo artículo 152 TCE), establece las bases y el régimen jurídico de la Salud Pública en la Unión Europea: “1. Aldefinirsey ejecutarse todas las politicas y acciones de la Unión se garantizará un alto nivel deprotección de la salud humana./ La acción de la Unión, que complementará las politicas nacionales, se encaminará a mejorar la salud pública, prevenir las enfermedades humanas y evitar las fuentes de peligro para la salud fisica $y$ psíquica. Dich a acción abarcará la luch a contra las enfermedades más graves y ampliamente difundidas, apoyando la investigación de su etiologia, de su transmisión y de su prevención, asi como la información y la educación sanitarias, y la vigilancia de las amenazas transfronterizas graves para la salud, la alerta en caso de tales amenazas y la luch a contra ellas. I La Unión complementará la acción de los Estados miembros dirigida a reproducir los daños a la salud producidos por las drogas, incluidas la información y la prevención./2. La Unión fomentará la cooperación entre los Estados miembros en los ámbitos contemplados en el presente artículo y, en caso necesario, prestará apoyo a su acción. Fomentará, en particular, la cooperación entre los Estados miembros destinados a mejorar la complementariedad de sus servicios de salud en las regiones fronterizas. / Los Estados miembros, en colaboración con la Comisión, coordinarán entre sí sus politicas y programas respectivos en los ámbitos a que se refiere el apartado 1. La Comisión, en estrecho contacto con los Estados miembros, podrá adoptar cualquier iniciativa útilpara fomentar dich a coordinación, en particular iniciativas tendentes a establecer orientaciones e indicadores, organizar el intercambio de

de aplicación de las disposiciones relativas a las libertades fundamentales establecidas en el Tratado en la medida en que se aplica a supuestos que guardan relación con los intercambios intracomunitarios, no se puede excluir de ningún modo que nacionales establecidos en Estados miembros distintos del Reino de España estén o hayan estado interesados en explotar farmacias en la Comunidad Autónoma de Asturias [...]”. 
mejores prácticas y preparar los elementos necesarios para el control y la evaluación periódicos. Se informará cumplidamente al Parlamento Europeo./ 3. La Unión y los Estados miembros favorecerán la cooperación con terceros paises y las organizaciones internacionales competentes en materia de salud pública./ 4. No obstante lo dispuesto en el apartado 5 del artículo $2^{27} y$ en la letra a) del articulo $6^{28}$, y de conformidad con la letra $k$ ) del apartado 2 del artículo $4^{29}$, el Parlamento Europeo y el Consejo, con arreglo al procedimiento legislativo ordinario y previa consulta al Comité Económico y Social y al Comité de las Regiones, contribuirán a la consecución de los objetivos del presente artículo adoptando, para hacer frente a los problemas comunes de seguridad:/ a) medidas que establezcan altos niveles de calidad y seguridad de los órganos y sustancias de origen humano, asi como de la sangre y derivados de la sangre; estas medidas no impedirán a ningún Estado miembro mantener o introducir medidas de protección más estrictas; / b) medidas en los ámbitos veterinario y fitosanitario que tengan como objetivo directo la protección de la salud pública;/ c) medidas que establezcan normas elevadas de calidad y seguridad de los medicamentos y productos sanitarios./ 5. El Parlamento Europeo y el Consejo, con arreglo al procedimiento legislativo ordinario y previa consulta al Comité Económico y Social y al Comité de las Regiones, podrán adoptar también medidas de fomento destinadas a proteger y mejorar la salud bumana y, en particular, a luchar contra las pandemias transfronterizas, medidas relativas a la vigilancia de las amenazas transfronterizas graves para la salud, a la alerta en caso de

${ }^{27}$ Véase: Tratado de 13 de diciembre de 2007 [Tratado sobre el funcionamiento de la Unión Europea [(Versión consolidada subsiguiente al "Tratado de Lisboa", de 13 de diciembre de 2007) (DOUE núm. 83, de 30 de marzo 2010)], artículo 2: "5. En determinados ámbitos y en las condiciones establecidas en los Tratados, la Unión dispondrá de competencia para llevar a cabo acciones con el fin de apoyar, coordinar o complementar la acción de los Estados miembros, sin por ello sustituir la competencia de éstos en dichos ámbitos./ Los actos juridicamente vinculantes de la Unión adoptados en virtud de las disposiciones de los Tratados relativas a estos ámbitos no podrán conllevar armonización alguna de las disposiciones legales y reglamentarias de los Estados miembros".

${ }^{28}$ Véase: Tratado de 13 de diciembre de 2007 [Tratado sobre el funcionamiento de la Unión Europea [(Versión consolidada subsiguiente al "Tratado de Lisboa" de 13 de diciembre de 2007) (DOUE núm. 83, de 30 de marzo 2010)], artículo 6: "La Unión dispondrá de competencia para llevar a cabo acciones con el fin de apoyar, coordinar o complementar la acción de los Estados miembros. Los ámbitos de estas acciones serán, en su finalidad europea: a) la protección y mejora de la salud humana; [...]".

${ }^{29}$ Véase: Tratado de 13 de diciembre de 2007 [Tratado sobre el funcionamiento de la Unión Europea (Versión consolidada subsiguiente al "Tratado de Lisboa" de 13 de diciembre de 2007) (DOUE núm. 83, de 30 de marzo 2010)], artículo 4: "2. Las competencias compartidas entre la Unión y los Estados miembros sea aplicarán a los siguientes ámbitos principales: [...].; k) los asuntos comunes de seguridad en materia de salud pública, en los aspectos definidos en el presente Tratado; [...]". 
tales amenazas y a la luch a contra las mismas, asi como medidas que tengan directamente como objetivo la protección de la salud pública en lo que se refiere al tabaco y al consumo excesivo de alcohol, con exclusión de toda armonización de las disposiciones legales y reglamentarias de los Estados miembros./ 6. El Consejo, a propuesta de la Comisión, podrá también adoptar recomendaciones para los fines establecidos en el presente artículo./ 7. La acción de la Unión en el ámbito de la salud pública respetará las responsabilidades de los Estados miembros por lo que respecta a la definición de su política de salud, así como a la organización y prestación de servicios sanitarios y atención médica. Las responsabilidades de los Estados miembros incluyen la gestión de los servicios de salud y de atención médica, así como la asignación de los recursos que se destinan a dichos servicios. Las medidas contempladas en la letra a) del apartado 4 se entenderán sin perjuicio de las disposiciones nacionales en materia de donaciones o uso médico de órganos y sangre".

El principio de subsidiariedad preside la acción de la Unión Europea en el ámbito de la salud, y más en concreto y con las precisiones enumeradas, en materia de salud pública. Del artículo 168 TFUE se deriva la existencia de una esfera competencial reservada a los Estados miembros, y por tanto, infranqueable para las Instituciones de la Unión.

Dicho de otro modo, los Estados miembros de la Unión Europea son competentes para organizar sus servicios sanitarios, tales como las oficinas de farmacia. Evidentemente, deben respetar el Derecho de la Unión, y en particular, las disposiciones del Tratado relativas a las libertades fundamentales. Entre ellas destaca la prohibición de que los Estados miembros establezcan o mantengan en vigor restricciones injustificadas al ejercicio de dichas libertades en el ámbito de la asistencia sanitaria ${ }^{30}$, pero corresponde a los mismos decidir que nivel de protección de la salud pública pretenden asegurar y de que manera debe alcanzarse ese nivel. Además, puede variar de un Estado miembro a otro y por eso se reconoce a los mismos un margen de apreciación ${ }^{31}$.

La Constitución Española de 1978 dispone en el artículo 4332: "1. Se re-

${ }^{30}$ Véase: Sentencias: Hartlauer, de 19 de mayo de 2009, Comisión/Italia, C-531/06, apartado 35 y Apothekerkammer des Saarlandes y otros, C-171/07 y C-172/07, apartado 18 .

${ }^{31}$ Véase: Sentencias: de 11 de septiembre de 2008, "Comisión/Alemania", C-141/07, apartado 51, y “Apothekerkammer des Saarlandes y otros”, C-171/07 y C-172/07, apartado 19.

${ }^{32}$ La Constitución italiana de 1947 será la primera que reconozca la existencia de un derecho a la salud en su artículo 32.1: "La República protege la salud, como fundamental derecho del individuo e interés de la colectividad, y garantiza curas gratuitas a los indigentes". Por su parte el "Preámbulo" de la Constitución francesa de 1946, que posteriormente pasa a la de 1958, señala: "La Nación asegura a todos, principalmente 
conoce el derecho a la protección de la salud. 2. Compete a los poderes públicos organizar y tutelar la salud pública a través de medidas preventivas y de las prestaciones y servicios necesarios. La Ley establecerá los derechos y deberes de todos al respecto. 3. Los poderes públicos fomentarán la educación sanitaria, la educación física y el deporte. Asimismo facilitarán la adecuada utilización del ocio". Se trata de un mandato claro para hacer efectivo el derecho a la salud. Este derecho aparece, además, claramente interconectado con otros preceptos del texto constitucional (artículos 40.2, 49, 50, 51, etc.), lo que hace que podamos afirmar que su significación tiene un sentido amplio. Pemán Gavín ${ }^{33}$ mantiene "que el derecho a la salud se proyecta en tres direcciones distintas que constituyen otras tantas dimensiones o aspectos del derecho a la salud: a) Derecho a la salud como derecho de todo ciudadano a las prestaciones sanitarias del Estado o, en otros términos, a la atención médica organizada y dispensada por los poderes públicos. b) Derecho a la salud como posición subjetiva en relación con la actividad desarrollada por los poderes públicos para proteger la salubridad pública (actividad relativa a aspectos como la sanidad ambiental, alimenticia, veterinaria, farmacéutica, etc.).c) Derecho a la salud como derecho de cada persona a que su propia salud no se vea amenazada ni dañada por acciones externas realizadas por cualquier sujeto público o privado. El derecho a la salud se comporta aquí como un derecho absoluto o de exclusión, oponible erga omnes: un derecho de la persona sobre un aspecto o cualidad propio defendible frente a todos".

Este mandato se completa con las normas del bloque constitucional

a los niños, a las madres y a los trabajadores ancianos, la protección de la salud [...]". La Constitución portuguesa de 1976 reconoce en su artículo 64: "[...] todos tendrán derecho a la protección de la salud y el deber de defenderla y promoverla". También los textos internacionales se han ocupado de esta materia. Concretamente, el "Preámbulo" de la Constitución de la Organización Mundial de la Salud, de 22 de julio de 1946, señala: "El goce del grado máximo de salud que pueda lograr es uno de los derechos fundamentales de todo ser humano [...]". La Declaración universal de los derecho del hombre, aprobada por la ONU el 10 de diciembre de 1948, en su artículo 25.1 considera: "Toda persona tiene derecho a un nivel de vida adecuado que le asegure, así como a su familia, la salud y el bienestar, y en especial la alimentación, el vestido, la vivienda, la asistencia médica y los servicios sociales necesarios [...]". La Carta Social Europea promulgada por el Consejo de Europa, en Turín, en 1961 en su parte I párrafo $11^{\circ}$, señala: "Toda persona tiene derecho a beneficiarse de cuantas medidas le permitan gozar del mejor estado de salud que pueda alcanzar". El Pacto Internacional de derechos económicos, sociales y culturales de 19 de diciembre de 1966, en su artículo 12.1 establece: "Los Estados Partes en el presente Pacto reconocen el derecho de toda persona al disfrute del más alto nivel posible de salud física y mental".

${ }^{33}$ Véase: Pemán Gavín, J., Derecho a la saludy Administración sanitaria, (Publicaciones del Real Colegio de España, Bolonia, 1989), pp. 79 y 80. 
que distribuyen las competencias en materia de salud entre el Estado y las Comunidades Autónomas.

El Estado, tal y como determina el artículo $149 \mathrm{CE}$, tiene competencia exclusiva sobre: "16a. Sanidad exterior. Bases y coordinación general de la sanidad ${ }^{34}$. Legislación sobre productos farmacéuticos" y "17ª Legislación básica y régimen económico de la Seguridad Social, sin perjuicio de la ejecución de sus servicios por las Comunidades Autónomas"35.

Las Comunidades Autónomas pueden asumir: las competencias sobre las materias relacionadas en el artículo 148.20 CE (“Asistencia social”) y 148.21 CE ("Sanidad e higiene"); las competencias sobre materias que el artículo 149.1 CE no reserva a la competencia exclusiva estatal; las competencias no contempladas en el artículo 149.1 CE; la competencia legislativa sobre materias de competencia estatal que una Ley Marco les atribuya; las facultades correspondientes a materia de titularidad estatal que por Ley Orgánica se les transfiera o delegue.

La Ley N 14/1986, de 25 de abril, General de Sanidad, reafirmó los pronunciamientos constitucionales en los artículos 38, 39, 40, 43 y 73. Además, esta configuración competencial origina y da vida al Sistema Nacional de Salud, que no es sino la conjunción de los diferentes servicios de salud de las Comunidades Autónomas debidamente coordinados, tal y como determina la Ley General de Sanidad, artículo 50: "En cada Comunidad Autónoma se constituirá un servicio de salud integrado por todos los centros, servicios y establecimientos de la propia Comunidad, Diputaciones, Ayuntamientos y cualesquiera otras Administraciones territoriales intracomunitarias, que estará gestionado, como se establece en los articulos siguientes, bajo la responsabilidad de la respectiva Comunidad Autónoma".

Cada Comunidad Autónoma tiene las atribuciones señaladas. Sin embargo, debo precisar que esa potestad no puede afectar a las "condiciones básicas" que proclama el artículo 149.1.1 ${ }^{\text {a }} \mathrm{CE}$, cuyo contenido es el siguiente: "El Estado tiene competencia exclusiva sobre [...] la regulación de las condiciones básicas que garanticen la igualdad de todos los españoles en el ejercicio de los derecho y en el cumplimiento de los deberes constitucionales".

${ }^{34}$ Como muestra, un botón. Véase: Real Decreto $N^{\circ} 1093 / 2010$, de 3 de septiembre, por el que se aprueba el conjunto mínimo de datos de los informes clínicos en el Sistema Nacional de Salud (BOE. de 16 de septiembre, núm. 225).

${ }^{35}$ Véase: Ley $N^{\circ}$ 16/2003, de 28 de mayo, de cohesión y calidad del Sistema Nacional de Salud, Disposición final primera: "Titulo competencial. 1. Esta ley se dicta al amparo del artículo 149.1.1 a $16^{a}$ y $17^{a}$ de la Constitución, que atribuye al estado competencia exclusiva en materia de bases y coordinación general de la sanidad y régimen económico de la seguridad social". 
Y completando el alcance de su significación se puede afirmar ${ }^{36}$ : "El recto entendimiento de este precepto no es una cuestión pacifica y tampoco acabada. En realidad no sería un titulo competencial propiamente en la medida en que - como ha dicho el TC-el precepto no se mueve en la lógica de las competencias compartidas: legislación básica estatal y normativa autonómica de desarrollo. Todo lo más podria decirse que es un titulo de funcionalidad horizontal o transversal, esto es, que cruza y puede incluso imponerse y prevalecer sobre otros títulos materiales especificos en atención a criterios objetivos y valores genéricos. Es decir, desde criterios finalistas. No se oculta a nadie, sin embargo, la necesidad de una prudente utilización y la conveniencia de una interpretación restrictiva para no desvirtuar indirectamente el sistema material de distribución competencial./ En todo caso, el TC ha señalado que las condiciones básicas a que apunta el precepto no pueden identificarse con los articulos 138 y 139.2, que no son títulos competenciales sino los límites del principio autonómico. Tampoco conecta desde el punto de vista competencial con el derecho a la igualdad del articulo 14. Finalmente, 'condiciones básicas' no es 'normativa básica' (como en otros apartados del propio artículo 149.1) y por tanto, como digo, no se mueve en la lógica de las competencias compartidas. Al contrario, el artículo 149.1.1 a habilitaría al Estado al establecimiento por entero de las condiciones básicas que garanticen la igualdad. Condiciones básicas que se predicarian de los derechos y deberes en si mismos considerados, no de los sectores o materias en que aquéllos se insertan./Estos planteamientos y otros de diversas sentencias del TC están todavia lejos de suponer una interpretación precisa, univoca y segura de la regla. [...]"

Las conclusiones que podemos extraer son las siguientes: primera, se podrán establecer las condiciones básicas que hacen referencia al contenido primario del derecho y a las posiciones jurídicas fundamentales, y el legislador competente deberá respetarlas de acuerdo con el orden constitucional de competencias; segunda, dentro de esas condiciones básicas se incluyen las facultades elementales, límites esenciales, deberes fundamentales, prestaciones básicas, premisas o presupuestos previos, etc., en relación con el objeto y su ámbito material. Este es el marco en el que se van a mover las potestades de las Comunidades Autónomas.

Y considero necesario hacer esta apreciación, porque el proceso de reforma estatutaria desarrollado en España, se justifica en determinadas disfunciones competenciales que nada tienen que ver con la determinación

${ }^{36}$ Véase: Martín Rebollo, L., Leyes administrativas (Pamplona, Aranzadi, 2010), pp. 206-208. 
de las condiciones básicas que proclama el artículo $149.1 .1^{\mathrm{a}} \mathrm{CE}^{37}{ }^{38}$.

b) Competencias compartidas entre el Estado y las Comunidades Autónomas. Las competencias compartidas (Estado-Comunidades Autónomas) comprenden la potestad legislativa, la potestad reglamentaria y la función ejecutiva, en el marco de las bases que fije el Estado en normas con rango de ley, excepto en los supuestos que se determinen de acuerdo con la Constitución. En el ejercicio de estas competencias, la Comunidad Autónoma puede establecer políticas propias.

i) Sanidad interior.

El ámbito de competencias en materia de sanidad interior, viene delimitado por las competencias que ostentan el Estado y los municipios. Por tanto, todo lo que no corresponde a la sanidad exterior (la que es producto o deriva de relaciones internacionales, de tal manera que su ordenación produce consecuencias jurídicas internas y externas a las fronteras del Estado español. Me refiero a la ordenación sanitaria de puertos, fronteras y aeropuertos, importación, exportación y tránsito de mercancías susceptibles de producir efectos sanitarios, a la relación con organismos sanitarios internacionales, etc.), ni al

${ }^{37}$ Véase: CARrasco Durán, M., Las competencias en la proposición de reforma del Estatuto de Autonomía para Andalucía: entre la norma y la realidad, en Revista Vasca de Administración Pública, 76 (2006), p. 40: “[...] el reparto de competencias entre el Estado y las Comunidades Autónomas viene aquejado por varias disfunciones, entre las cuales destacarían la intromisión del Estado en ámbitos competenciales atribuidos por los Estatutos de Autonomía a las Comunidades Autónomas a partir de una interpretación extensa del contenido de las competencias de aquél, la carencia de posibilidades de participación de las Comunidades Autónomas en la adopción de normas y decisiones sobre materias que corresponden a la competencia del Estado, pero que tienen un alto interés para aquéllas por afectar a importantes ámbitos de la vida económica y social autonómica, y la falta de recepción expresa en el Estatuto de Autonomía de algunas políticas sobre fenómenos de la realidad social que han cobrado una importancia que no tenían en el momento en que aquel fue redactado o sobre nuevas actividades que han adquirido importancia debido a adelantos científicos producidos con posterioridad a la redacción de aquel. [...]".

${ }^{38}$ Véase: Villalba Pérez, Francisca, Situación jurídica actual de las oficinas de farmacia en España, en Noticias de la Unión Europea, 251 (2005), p. 60: “[...], ante la falta de una legislación básica clarificadora del modelo de oficina de farmacia española y de la necesaria concreción de los criterios de planificación, las Comunidades Autónomas se han lanzado a regular cada una a su forma -según el matiz político de sus órganos de gobierno- el régimen de las oficinas de farmacia. El resultado es un absoluto caos legislativo y una maraña interminable de procedimientos. Basta con comparar las distintas leyes de ordenación farmacéutica ya aprobadas o los proyectos en trámite, para comprobar que algunos aspectos esenciales de su regulación difieren de tal forma que han desdibujado las condiciones básicas garantizadoras de la igualdad en el ejercicio de los derechos y en el cumplimiento de los deberes constitucionales que proclama el artículo 149.1.1 de la CE”. 
ámbito municipal (establecido en la Ley $\mathrm{N}^{\circ} / 1985$, de 2 de abril, de Bases del régimen local, artículo 25), comprendería el ámbito de sanidad interior cuya competencia comparte el Estado y la Comunidad Autónoma.

A partir de la distribución constitucional de competencias determinada, se aceptó la diferenciación entre la materia propia de salud pública, asumible por todas las Comunidades Autónomas, y la competencia en materia de asistencia sanitaria que en la medida en que se entendía formaba parte de la Seguridad Social, sólo podía ser asumida por las Comunidades Autónomas si era incluida en su Estatuto de Autonomía, y así ha sido.

Un elemento clave en la delimitación del ámbito competencial de las Comunidades Autónomas, son sus respectivas Leyes de Salud. Por ejemplo, la Comunidad Autónoma de Andalucía en la Ley N²/1998, de 15 de junio, de salud de Andalucía (BOJA. de 4 de julio, núm. 74), precisa en el artículo 35: "La Administración de la Junta de Andalucía ejercerá las competencias que tiene atribuidas en materia de sanidad interior, higiene y salud pública, asistencia y prestaciones sanitarias y ordenación farmacéutica, de acuerdo con lo previsto en el Estatuto de Autonomía para Andalucia". También determina que "La Consejeria de Salud, en el marco de la acción politica fijada por el Consejo de Gobierno, ejercerá las funciones de ejecución de las directrices y los criterios generales de la politica de salud, planificación y asistencia sanitaria, asignación de recursos a los diferentes programas y demarcaciones territoriales, alta dirección, inspección y evaluación de las actividades, centros y servicios sanitarios y aquellas otras competencias que le estén atribuidas por la legislación vigente" (artículo 36). En términos similares, han redactado sus respectivas leyes de salud, las demás autonomías españolas.

En definitiva la sanidad interior comprende todas las prestaciones de asistencia sanitaria en sus diversas modalidades con independencia de su sistema de financiación. Se trata de una competencia compartida por cuanto la distribución constitucional de competencias así lo ha establecido, correspondiendo a las Comunidades Autónomas el desarrollo legislativo y la ejecución de la legislación básica del Estado, así como el establecimiento y ejecución de su propia normativa respecto a un ámbito que desde un punto de vista material presta en su integridad.

ii) Servicios y prestaciones sanitarias -en especial la farmacéutica-, sociosanitarias y de salud mental de carácter público.

El catálogo de prestaciones del Sistema Nacional de Salud tiene por objeto garantizar las condiciones básicas y comunes para una atención integral, continuada y en el nivel adecuado de atención. Se consideran prestaciones de atención sanitaria del Sistema Nacional de Salud los servicios o conjunto de servicios preventivos, diagnósticos, terapéuticos, rehabilitadotes y de promoción y mantenimiento de la salud dirigidos a los ciudadanos. 
Dicho catálogo comprende las prestaciones correspondientes a salud pública, atención primaria, atención especializada, atención sociosanitaria, atención de urgencias, la prestación farmacéutica, la ortoprotésica de productos dietéticos y de transporte sanitario ${ }^{39}$.

Dentro de la asistencia especializada se incluye la salud mental. La LGS en su artículo 20 procede a la plena integración de las actuaciones relativas a la salud mental en el sistema sanitario general y de la total equiparación del enfermo mental a las demás personas que requieren servicios sanitarios y sociales, y también lo hace el Real Decreto 63/1995, de 20 de enero, del Ministerio de Sanidad y Consumo, que regula la ordenación de prestaciones sanitarias en el Sistema Nacional de Salud (BOE de 10 de febrero, núm. $35)$.

iii) Salud pública.

La prestación de salud pública es el conjunto de iniciativas organizadas por las Administraciones para preservar, proteger y promover la salud de la población. Es una combinación de ciencias, habilidades y actitudes dirigidas al mantenimiento y mejora de la salud de todas las personas a través de acciones colectivas o sociales.

La salud pública concentra su actividad en la vigilancia, planificación, prevención y protección de la salud. Para todo ello, debe orientar su acción en dos grandes áreas. De una parte, dotarse de un sistema de información, vinculado a la identificación de las necesidades, la planificación y la evaluación de los servicios desde una perspectiva de salud y la detección de segmentos de población mal cubiertos o sin acceso real a los servicios, permitiendo que la información sea la base de la correcta toma de decisiones. De otra parte, desarrollar las intervenciones en el ámbito comunitario, vinculadas a la prestación de servicios o al desarrollo de programas que pueden realizarse directamente desde los servicios de salud pública, desde otras estructuras o mediante una combinación de ambas opciones.

Las prestaciones en este ámbito comprenden las siguientes actuaciones: i) La información y vigilancia epidemiológica; $i i$ ) La protección de la salud; iii) La promoción de la salud; iv) La prevención de las enfermedades y de las deficiencias; $v$ ) La vigilancia y control de los posibles riesgos para la salud derivados de la importación, exportación o tránsito de mercancías y del tráfico internacional de viajeros, por parte de la Administración sanitaria competente; vi) La promoción y protección de la sanidad ambiental; vii) La promoción y protección de la salud laboral; vii) La promoción de la seguridad alimentaria.

${ }^{39}$ Véase: Ley $N^{\circ}$ 16/2003, de 28 de mayo, de cohesión y calidad del Sistema Nacional de Salud, artículo 7.1. 
Estas prestaciones de salud pública se ejercen con un carácter de integralidad, a partir de las estructuras de salud pública de las Administraciones y de la infraestructura de atención primaria del Sistema Nacional de Salud ${ }^{40}$.

Respecto a las actuaciones coordinadas en materia de salud pública cobra especial relevancia la declaración de actuación coordinada que obliga a todos los integrantes del Sistema Nacional de Salud a: i) Responder a situaciones de especial riesgo o alarma para la salud pública; ii) Dar cumplimiento a acuerdos internacionales, así como a programas derivados de las exigencias de la normativa emanada de la Unión Europea, cuando su cumplimiento y desarrollo deba ser homogéneo en todo el Estado Para la realización de actuaciones coordinadas podrá acudirse, entre otros, a los siguientes mecanismos: i) Utilización común de instrumentos técnicos; ii) Configuración de una Red de Laboratorios de Salud Pública; iii) Definición de estándares mínimos en el análisis e intervención sobre problemas de salud; iv) Coordinación de sistemas de información epidemiológica y de programas de promoción, protección de la salud, prevención y control de las enfermedades más prevalentes, cuando sus efectos trasciendan el ámbito autonómico ${ }^{41}$.

c) Ejecución de la legislación española en materia de productos farmacéu ticos. El artículo 149.1.16 CE establece la competencia exclusiva del Estado en materia de legislación sobre productos farmacéuticos, correspondiendo a la Comunidad Autónoma, en virtud de lo establecido en su Estatuto la ejecución de la legislación estatal en materia de productos farmacéuticos ${ }^{42}$. Estas competencias, comprenden la función ejecutiva que incluye la potestad de organización de su propia administración y, en general, aquellas funciones y actividades que el ordenamiento atribuye a la Administración Pública y, cuando proceda, la aprobación de disposiciones reglamentarias para la ejecución de la normativa del Estado.

Todo ello responde no sólo a la distribución competencial aludida, sino también a la necesidad de incorporar las disposiciones comunitarias (Unión Europea) teniendo presente el concepto de competencias en relación con la aplicación del derecho comunitario, y establece que comprenden el desarrollo y la ejecución de la normativa de la Unión Europea cuando afecte al ámbito de las competencias de la Comunidad Autónoma -es una forma de incorporar al Estatuto de Autonomía la doctrina que viene aplicando el Tribunal Constitucional en relación con las competencias de las Comunidades Autónomas para desarrollar y ejecutar el derecho comunitario, según la cual estas facultades corresponde al ente, ya Estado, ya Comunidad Autónoma,

\footnotetext{
${ }^{40}$ Ibíd., artículo 11.

${ }^{41}$ Ibíd., artículo 65.2.

${ }^{42}$ Véase: Barranco Vela, Rafael (director) - Bombillar Sáenz, Francisco Miguel (coordinador), El acceso al medicamento (Granada, Comares, 2010).
} 
que tenga competencia para llevar a cabo la actuación de desarrollo normativo y ejecución de la que se trate sobre cada materia conforme al reparto interno de competencias ${ }^{43}$-, así como el control de la financiación selectiva y no indiscriminada de medicamentos en función de la utilidad terapéutica de los mismos y de su necesidad para mejorar la salud de los ciudadanos (que corresponderá al Estado). De este modo se garantiza un sistema de precios de referencia, un sistema de farmacovigilancia y un abanico de posibilidades terapéuticas igual para todos los ciudadanos con independencia de la Comunidad Autónoma donde residan.

Esta ejecución de la legislación estatal implicará la identificación, cuantificación, evaluación y prevención de los riesgos del uso de los productos farmacéuticos una vez comercializados, permitiendo así el seguimiento de sus posibles efectos adversos, configurándose un sistema en el que las distintas Administraciones sanitarias han de realizar lo necesario para recoger, elaborar y, en su caso, procesar toda la información útil para la supervisión de medicamentos y, en particular, la información sobre reacciones adversas a los mismos, así como para la realización de cuantos estudios se consideren necesarios para evaluar su seguridad.

d) Participación en la planificación y coordinación estatal en materia de sanidad y salud pública. Siguiendo la estela de la organización tradicional de la sanidad española, la Ley General de Sanidad estableció los mecanismos de cooperación y coordinación de carácter general, a saber: $i$ ) el Consejo Interterritorial del Sistema Nacional de Salud ${ }^{44}$; ii) los convenios

${ }^{43}$ Véase: Ley $\mathrm{N}^{\circ} 29 / 2006$, de 26 de julio, sobre garantías y uso racional de los medicamentos y productos sanitarios (BOE. de 27 de julio de 2006, núm. 178), "Exposición de Motivos", II: “[...]. Por este motivo se incorporan a través de esta Ley a nuestro ordenamiento jurídico la Directiva 2004/27/CE del Parlamento Europeo y del Consejo, de 31 de marzo de 2004, que modifica la Directiva 2001/83/CE, por la que se establece un código comunitario sobre medicamentos de uso humano, y la Directiva 2004/28/CE del Parlamento Europeo y del Consejo, de 31 de marzo de 2004, que modifica la Directiva 2001/82/CE, por la que se establece un código comunitario sobre medicamentos veterinarios. Además, también se asegura la armonización de nuestra normativa con el Reglamento (CE) num. 726/2004, por el que se establecen los procedimientos comunitarios para la autorización y el control de los medicamentos de uso humano y veterinario y por el que se crea la Agencia Europea de Medicamentos".

${ }^{44}$ Véase: Sala Arquer, J. M. - Villar Rojas, F., Análisis de la cooperación en un sector determinado: la sanidad pública, en Derecho y Salud, 10 (2002) 1, pp. 83-84, donde dan cuenta del contenido de un documento interno del Ministerio de Sanidad en el que se describe lo ocurrido: "La Ley (se está refiriendo a la LGS) preveía una coordinación planificada y lo que ha existido ha sido una coordinación consensuada en el seno del Consejo Interterritorial. El Ministerio ha hecho dejación de su capacidad de regular para buscar la vía del consenso". Véase: Ley $N^{\circ}$ 16/2003, de 28 de mayo, de cohesión y calidad del Sistema Nacional de Salud, capítulo X. 
interadministrativos, multilaterales y bilaterales, como instrumento para formalizar acuerdos en asistencia sanitaria y salud pública; $i i i$ ) los Planes de Salud, como instrumento para ordenar y programar las actividades sanitarias; y iv) los criterios generales de coordinación ${ }^{45}$.

También debo señalar como otros medios de cooperación y coordinación: la organización nacional de trasplantes, la red de vigilancia epidemiológica, la agencia de seguridad alimentaria y el sistema de farmacovigilancia.

La Ley $\mathrm{N}^{\circ} 16 / 2003$, de 28 de mayo, de cohesión y calidad del Sistema Nacional de Salud, en buena medida tiene por objeto propiciar la coordinación y cooperación de las Administraciones públicas sanitarias, en el ejercicio de sus respectivas competencias, de modo que se garantice la equidad, la calidad y la participación social en el sistema Nacional de Salud, así como la colaboración activa de este en la reducción de las desigualdades en salud (artículo 1). Asimismo, entre los principios generales que informan esta ley se incluye en el artículo 2: “c) La coordinación y la cooperación de las Administraciones públicas sanitarias para la superación de las desigualdades en salud".

Dicha participación se hace efectiva al elaborar el catálogo de prestaciones del Sistema Nacional de Salud y más en concreto mediante la cartera de servicios acordada en el seno del Consejo Interterritorial del Sistema Nacional de Salud. Sin duda, este va a ser el elemento clave.

Evidentemente esta participación se hará efectiva, en términos generales, a través de los mecanismos que establecen los Estatutos de Autonomía, y de los sectoriales enumerados en los párrafos anteriores ${ }^{46} . Y$ todo ello, porque la planificación y coordinación son imprescindibles si se quiere asegurar la igualdad efectiva de todos en el derecho a la protección de la salud ${ }^{47}$.

${ }^{45}$ Véase: Real Decreto $N^{\circ} 1093 / 2010$, de 3 de septiembre, por el que se aprueba el conjunto mínimo de datos de los informes clínicos en el Sistema Nacional de Salud (BOE. de 16 de septiembre, núm. 225).

${ }^{46}$ Véase: STC 32/1983, F.J. 2º apartado d): “[...] la coordinación general sanitaria se ejercerá por el Estado, fijando medios y sistemas de relación para facilitar la información recíproca, la homogeneidad técnica en determinados aspectos y la acción conjunta de las Administraciones Públicas sanitarias en el ejercicio de sus respectivas competencias, de tal modo que se logre la integración de actos parciales en la globalidad del Sistema Nacional de Salud".

${ }^{47}$ Véase: MuÑoz Machado, S., La formación y crisis de los servicios sanitarios públicos (Madrid, Alianza Editorial, 1995), pp. 110-113: “[...] creo que se comprendería mal lo que la coordinación significa si la legislación sanitaria básica se empeñara en configurarla sobre el principio único de permitir al Estado imponer a las Comunidades Autónomas criterios de política sanitaria unilateralmente elaborados. Lo que la coordinación impone, por el contrario, es una conjunción de esfuerzos y una coparticipación en la formulación de objetivos que las diferentes partes que integran un sistema sanitario único deben alcanzar [...]. En definitiva, este tipo de instrumentos (los instrumentos de coordinación) deben usarse de manera que sus contenidos sean aceptados antes 
2. Ningún acto de aplicación de las libertades fundamentales establece normas de acceso a las actividades del ámbito farmacéutico.

La Directiva N ${ }^{\circ} 2005 / 36 / C E$ del Parlamento Europeo y del Consejo de 7 de septiembre de 2005, relativa al reconocimiento de cualificaciones profesionales, considerando vigésimo sexto, recoge, en esencia, el segundo considerando de la Directiva $N^{\circ}$ 85/432/CEE del Consejo, de 16 de septiembre de 1985, relativa a la coordinación de las disposiciones legales, reglamentarias y administrativas para ciertas actividades farmacéuticas en los siguientes términos ${ }^{48}$ : "La presente Directiva no coordina todas las condiciones de acceso a las actividades del ámbito farmacéutico y su ejercicio. En concreto, la distribución geográfica de las farmacias y el monopolio de dispensación de medicamentos deben seguir siendo competencia de los Estados miembros. Por otra parte, la presente Directiva no altera las disposiciones legales, reglamentarias y administrativas de los Estados miembros que probiben a las empresas la práctica de ciertas actividades farmacéuticas o imponen ciertas condiciones a dich a práctica".

El artículo primero de la Directiva $\mathrm{N}^{\circ}$ 2005/36/CE dispone: "La presente Directiva establece las normas según las cuales un Estado miembro que subordina el acceso a una profesión regulada o su ejercicio, en su territorio, a la posesión de determinadas cualificaciones profesionales [...] reconocerá para el acceso a dicha profesión y su ejercicio las cualificaciones profesionales adquiridas en otro $u$ otros Estados miembros [...] y que permitan al titular de las mencionadas cualificaciones ejercer en él la misma profesión" ${ }^{9}$.

de ser aprobados. Esto es, sencillamente, capital; sobre todo porque es una de las claves de funcionamiento de los sistemas autonómicos peor entendida, y menos practicada, hasta hoy, entre nosotros".

${ }^{48}$ Para un estudio más detallado de estas cuestiones Véase: Pérez Gálvez, Juan Francisco, Reconocimiento del título de farmacéutico especialista en la Unión Europea: farmacia hospitalaria Comentario a la STJCE (Sala Segunda) de 8 de mayo de 2008, en Noticias de la Unión Europea, 306 (2010), pp. 108-110.

${ }^{49}$ Véase: Directiva No 2005/36/CE del Parlamento Europeo y del Consejo, de 7 de septiembre de 2005, artículo 45: "Ejercicio de las actividades profesionales de farmacéutico. 1 . A efectos de la presente Directiva, las actividades de farmacéutico serán aquellas cuyo acceso y ejercicio estén subordinados en uno o varios Estados miembros a condiciones de cualificación profesional y que estén abiertas a los titulares de alguno de los títulos de formación mencionados en el punto 5.6.2 del anexo V. 2. Los Estado miembros velarán por que los titulares de un titulo profesional de formación universitaria o de un nivel reconocido equivalente en farmacia que cumplan las condiciones indicadas en el articulo 44 sean habilitados al menos para el acceso a las actividades siguientes y su ejercicio, a reserva de la exigencia, en su caso, de una experiencia profesional complementaria: a) preparación de la forma farmacéutica de los medicamentos; b) fabricación y control de medicamentos; c) control de los medicamentos en un laboratorio de control de medicamentos; d) almacenamiento, conservación y distribución de medicamentos al por mayor; e) preparación, 
Debo señalar que ni la Directiva $\mathrm{N}^{\circ} 2005 / 36$, ni ningún otro acto de aplicación de las libertades fundamentales establecen normas de acceso a las actividades del ámbito farmacéutico destinadas a establecer las condiciones en las que se pueden crear nuevas farmacias en el territorio de los estados miembros.

Ciertamente, el artículo 45, apartado 5, de la Directiva $N^{\circ} 2005 / 36$ dispone que, cuando en un estado miembro exista desde la fecha de 16 de septiembre de 1985 una oposición para seleccionar a los farmacéuticos que se designarán como titulares de las nuevas farmacias, cuya creación se haya decidido en virtud de un sistema nacional de distribución geográfica, dicho Estado miembro podrá mantener el desarrollo de dicha oposición y someter a ella a los nacionales de otros Estados miembros.

Este es el supuesto en el que nos encontramos. En el año 2002, existía en España tal oposición, y el procedimiento controvertido en los litigios principales referenciados corresponde a dicha oposición. Por consiguiente, España puede mantener tal procedimiento y aplicarlo a todos los farmacéuticos, siempre que las normas que lo regulan sean conformes con el Derecho de la Unión. De lo expuesto se desprende, que las normas que rigen el procedimiento controvertido no están sujetas a lo dispuesto por el Tratado en lo que respecta a las exigencias relativas a la ordenación territorial de las farmacias, puesto que este elemento queda fuera del ámbito de aplicación de la Directiva $N^{\circ} 2005 / 36$.

La Directiva $N^{\circ} 2005 / 36$, artículo primero, no contiene normas relativas al establecimiento de las oficinas de farmacia ni sobre los requisitos de explotación de las mismas, ni más concretamente, sobre su ordenación territorial u ordenación farmacéutica (como usualmente se le denomina). En la doctrina, cuando hablamos de ordenación farmacéutica nos estamos refiriendo: “[...]. Atendiendo a una óptica material, ya la STC 32/1987, de 28 de abril (FJ3) ofrece una primera aproximación al señalar que la competencia autonómica de ordenación farmacéutica "debe entenderse referida a la ordenación de los establecimientos de venta al público de productos farmacéuticos" [...].

control, almacenamiento y dispensación de medicamentos en las farmacias abiertas al público; f) preparación, control, almacenamiento y dispensación de medicamentos en los hospitales; g) difusión de información y asesoramiento sobre medicamentos. [...]. 5. Cuando en un Estado miembro exista desde la fecha de 16 de septiembre de 1985 una oposición para seleccionar entre los titulados indicados en el apartado 2 a los que se designarán como titulares de las nuevas farmacias, cuya creación se haya decidido en virtud de un sistema nacional de distribución geográfica, dicho Estado miembro podrá, no obstante lo dispuesto en el apartado 1, mantener el desarrollo de dicha oposición y someter a ella a los nacionales de los Estado miembros que posean alguno de los títulos de formación de farmacéutico mencionados en el punto 5.6.2 del anexo $V$ o se beneficien de los dispuesto en el articulo 23 [relativo a los derechos adquiridos]". 
Desde una perspectiva funcional, la clave está en el término "ordenación" que, como ha indicado Garrido Falla, puede describirse como el conjunto de reglas que rigen la organización o funcionamiento de determinada actividad, por lo que la ordenación viene a equipararse a la reglamentación. Equivalencia, a la postre, entre ordenación y regulación, como resulta de la jurisprudencia constitucional (SS 57/1992, de 9 de abril, y 68/1992, de 30 de abril) y de la propia legislación (Ley de ordenación del transporte terrestre, Ley de ordenación del comercio minorista, etc.). Por ello la ordenación farmacéutica se configura como una competencia normativa, según señala la STC 1/82 (distinguiéndola de la competencia ejecutiva sobre productos farmacéuticos) y la doctrina. Se comparte pues el criterio de Penacho Martínez de que la competencia de ordenación farmacéutica es esencialmente normativa, comprendiendo también normas de organización y posibles actos de ejecución. [...].

En fin, es opinión común que la llamada "ordenación farmacéutica" debe relacionarse con la dispensación del medicamento a los destinatarios finales $\mathrm{y}$ con las actuaciones anteriores o posteriores pero directamente conectadas con esta fase de ciclo farmacéutico; siendo de naturaleza normativa y comprendiendo fundamentalmente la planificación y autorización de las oficinas de farmacia privada, las farmacias hospitalarias, botiquines rurales, etc., esto es, los llamados establecimientos farmacéuticos, diferenciándose claramente de los productos farmacéuticos; [...], destacando su íntima conexión con la sanidad y, por consiguiente, su consideración como un subsistema del sistema sanitario ${ }^{50}$.

La Ley $\mathrm{N}^{\circ}$ 16/1997, de 25 de abril, de Regulación de servicios de las oficinas de farmacia, en su artículo 2, establece que las Comunidades Autónomas determinarán los criterios específicos de planificación para la autorización de nuevas oficinas de farmacia que debe realizarse teniendo como referente la planificación sanitaria y en concreto las unidades básicas de atención primaria.

En España la competencia sobre ordenación de los servicios y establecimientos farmacéuticos, así como las obligaciones que se derivan de la atención farmacéutica que se presta en los mismos a los ciudadanos, garantizando, en todo momento, un acceso adecuado y de calidad a los medicamentos, fomentando su uso racional y propiciando la mejora de sus niveles de salud, corresponde a las Comunidades Autónomas.

La planificación territorial se efectuará tomando como referencia las zonas

${ }^{50}$ Véase: Razquin Lizarraga, J. A., La competencia de las Comunidades autónomas y de la Comunidad Foral de Navarra sobre ordenación farmacéutica, en Revista Jurídica de Navarra, 20 (1995), pp. 80-82. 
básicas de salud, fijadas en el mapa de atención primaria de salud. Estas zonas servirán de referencia para establecer reglamentariamente las "Unidades Territoriales Farmacéuticas" o circunscripciones equivalentes, que se configuran como la base de la planificación. Estas unidades se delimitan atendiendo a los factores geográficos, socioeconómicos y demográficos ${ }^{51}$.

El vigésimo sexto considerando de la Directiva $N^{\circ} 2005 / 36$, en virtud del cual ésta no coordina todas las condiciones de acceso a las actividades del ámbito farmacéutico, de manera que, en particular, la distribución de las farmacias en el territorio sigue siendo competencia de los Estados miembros, corrobora lo expuesto.

Es por ello, que las normas de Derecho interno controvertidas, relativas a la ordenación territorial, deben examinarse a la luz de lo dispuesto por el Tratado, y, en particular, por su artículo 49.

\section{RESOLUCIÓN QUE ADOPTA}

\section{EL TRIBUnal SOBRE la libertad DE ESTABleCimiento DE}

\section{FARMACIAS}

\section{La normativa española constituye una restricción a la libertad de esta-}

\section{blecimiento.}

Una vez detallado el grupo normativo regulador y justificado que ningún acto de aplicación de las libertades fundamentales establece normas de acceso a las actividades del ámbito farmacéutico, debo analizar algunas cuestiones relevantes de la resolución judicial adoptada.

El órgano jurisdiccional remitente, en su primera cuestión prejudicial pregunta, en esencia, si el artículo 49 TFUE se opone a una normativa nacional, como la controvertida en los litigios principales, que impone límites a las autorizaciones de farmacias, al disponer determinados módulos de población y unas distancias mínimas ${ }^{52}$.

La doctrina del TJUE tiene establecido que constituye una restricción en el sentido del artículo 49 TFUE cualquier medida nacional que, aun cuando sea de aplicación sin discriminación por razón de la nacionalidad, pueda obs-

\footnotetext{
${ }^{51}$ Véase: Pérez GÁlvez, Juan Francisco, Transmisibilidad, caducidad y cotitularidad de las farmacias (Comentario a la STC 109/2003, de 5 de junio), en Revista Jurídica de Navarra, 36 (2003), pp. 185-214.

${ }^{52}$ Los límites que ya han sido expuestos en este trabajo los relaciona la sentencia en el apartado 51: “- en principio, en cada zona farmacéutica, sólo podrá crearse una farmacia por módulo de 2.800 habitantes; - tan sólo podrá crearse una farmacia adicional si se sobrepasa dicha proporción, la cual se creará por la fracción superior a 2.000 habitantes, y - cada farmacia deberá respetar una distancia minima respecto de las farmacias preexistentes, que es, por regla general, de 250 metros".
} 
taculizar o hacer menos atractivo el ejercicio, por parte de los nacionales de la Unión, de la libertad de establecimiento garantizada por el Tratado ${ }^{53}$.

Evidentemente, una normativa nacional como la controvertida en la sentencia, constituye una restricción de la libertad de establecimiento en el sentido del artículo 49 TFUE. Sin embargo, será necesario estudiar, si existe justificación a la restricción de la libertad de establecimiento.

\section{Justificación.}

a) Normas no discriminatorias por razón de nacionalidad y justificadas por razones de interés general.

La jurisprudencia del TJUE, ha determinado en reiteradas ocasiones que las restricciones a la libertad de establecimiento que se apliquen sin discriminación de nacionalidad, pueden estar justificadas por razones de interés general ${ }^{54}$. En la sentencia que estoy comentando, debo destacar que las normas controvertidas se aplican sin discriminación por razón de nacionalidad.

Respecto a la justificación por razones de interés general, debo advertir que en España, el concepto de interés general/interés público, ha sido tratado con profusión ${ }^{55}$. Parte de la doctrina ${ }^{56}$ considera que la conexión con el interés general constituye la vinculación mínima y necesaria que todo acto de la Administración debe tener con el Derecho ${ }^{57}$ para que esa actuación pueda considerarse conforme al ordenamiento jurídico y respetar así la exigencia que deriva del principio de legalidad y, en última instancia, del principio de juridicidad. En nuestro Derecho la norma que establece que la

${ }^{53}$ Véase: SSTJUE: 14 de octubre de 2004, “Comisión /Países Bajos”, C-299/02, apartado 15; 21 de abril de 2005, "Comisión/Grecia”, C-140/03, apartado 27.

${ }^{54}$ Véase la sentencia del Tribunal de Justicia de las Comunidades Europeas (Gran Sala) de 19 de mayo de 2009.

${ }^{55}$ Véase: SSTS: 27 de octubre de 1962; 31 de octubre de 1970; 24 de abril de 1973; 14 de enero de 1976; 16 de junio de 1978; 25 de julio de 1979; 14 de diciembre de 1979; 28 de septiembre de 1983; 3 de diciembre de 1985; 30 de septiembre de 1986; 19 de julio de 1988, entre otras.

${ }^{56}$ Véase: Beladiez Rojo, M., La vinculación de la Administración al Derecho, en Revista de Administración Pública, 153 (2000), pp. 328-329.

${ }^{57}$ Véase: STS de 6 de abril de 1979 (Ar. 1571): “[...],puesto que también si la Administración por razones de interés público regula el condicionado de una póliza sustrayéndole a la voluntad de los contratantes, es evidentemente que se conculcaría dicho interés consintiendo después de su vigencia la aplicación de unas cláusulas ya derogadas, aunque estén aún reflejadas en el documento formal suscrito por los contratantes y constituyan sus voluntades contractuales, máxime cuando como en este caso ocurre, las nuevas disposiciones legales admiten su acomodación a ellas, porque entonces esas cláusulas derogadas no son vivo reflejo de las nuevas normas de interés público que exige el nuevo condicionado de tales pólizas [...]”. 
Administración actúa en beneficio del interés general es el artículo 103.1 de la Constitución que dispone lo siguiente: "La Administración Pública sirve con objetividad los intereses generales y actúa de acuerdo con los principios de eficacia, jerarquí, descentralización, desconcentración y coordinación, con sometimiento pleno a la Ley y al derecho". Vínculo positivo que la Administración nunca podrá desconocer, ya que en tal caso habría vulnerado no sólo el principio de legalidad - no ha respetado la norma jurídica que establece que sólo podrá actuar en beneficio del interés general-, sino que, además, habría desconocido el principio de juridicidad al haber actuado sin que exista la norma atributiva de competencia.

Quizás sea este el momento de acotar en que consiste esa entelequia que utilizamos los juristas con asiduidad: "interés público/interés general" 58 . Cabe preguntarse si cuando hablamos de interés público, estamos hablando de un concepto jurídico indeterminado, o nos referimos a una arbitrariedad de los poderes públicos. Se admite por la doctrina que estamos en el primer supuesto $^{59}$, y que es posible su control judicial.

Así ha sido explicado, aunque con matices, por Alejandro Nieto ${ }^{60}$ : “los intereses generales son indefinidos (en cuanto que ninguna norma lo hace) e indefinibles objetivamente (en cuanto que no existe criterio objetivo alguno para realizar esta operación), con la consecuencia de que su función primordial sigue siendo ideológica, es decir, de cobertura legitimadora de los Poderes públicos para justificar el contenido de sus decisiones e incluso su mera intervención formal en las relaciones sociales. Constatado esto, el análisis ha demostrado, sin embargo, que no es lícito detenerse aquí, ya que la función ideológica tiene una segunda vertiente no menos importante: la

${ }^{58}$ Véase: MARTín MAteo, Ramón, La sustantividad del derecho administrativo, en Revista de Administración Pública, 53, (1967), p. 47: “[...]. Pero siempre habrá de concluirse sobre la presencia o no del interés público, porque esta noción es, en sí metajurídica, cuya trascendencia para el mundo del Derecho sólo resulta de su concreción normativa y de la decisión al respecto del órgano estatal competente. [...]. Queda, pues, demostrado que la consecución de finalidades de interés público, bien que inherente a todas las actividades de la Administración, ni es exclusiva de ésta ni implica por sí la utilización de un régimen imperativo. [...]".

${ }^{59}$ Véase: Gimeno Feliu, J. Ma., Sistema económico y derecho a la libertad de empresa versus reservas al sector público de actividades económicas, en Revista de Administración Pública, 135 (1994), p. 209. También hace referencia a la STC 68/1984, de 11 de junio: "No cabe desconocer que la facultad atribuida por la Constitución al Estado para definir el interés general, concepto abierto e indeterminado, llamado a ser aplicado a las respectivas materias, puede ser controlado, frente a posibles abusos, y a posteriori, por este Tribunal".

${ }^{60}$ Véase: Nieto, Alejandro, La Administración sirve con objetividad los intereses generales, en Estudios sobre la Constitución Española (Homenaje al profesor Eduardo Garcia de Enterría) (Madrid, Cívitas, 1991), III, pp. 2.185-2.253. 
limitación del Poder. Si el Poder se legitima por los intereses generales, es claro que dicha legitimación únicamente opera cuando existen tales intereses y fuera de ellos la actuación se convierte en ilegítima”. También García de Enterría expresa ${ }^{61}$ : "pero me parece que no puede caber ninguna duda en estos dos asertos esenciales: primero, que el término "interés general” es, en efecto, un "concepto jurídico indeterminado" en cuanto es utilizado por las Leyes; y, segundo, que justamente por ello, y sólo por ello, el juez puede controlar -y controla de hecho- su aplicación por la Administración. [...]. Que la idea de interés público o de interés general es un "concepto legal" (mejor que "jurídico", para evitar el equívoco de que se trate de cualquier construcción intelectual y abstracta, como podría dejarse suponer) de alcance indeterminado, es la evidencia misma, desde el momento en que las leyes lo emplean con frecuencia y porque su alcance es, evidentemente, indeterminado, pues no permite una aplicación precisa, determinada e inequívoca en un supuesto dado. [...]. Interés general o interés público son guías claras que utiliza el constituyente para organizar instituciones o actuaciones públicas. En modo alguno podrían interpretarse, precisamente, como expresiones que habiliten a los titulares de los poderes públicos para acordar lo que su buen querer o imaginación puedan sugerirles, como habilitantes de una verdadera discrecionalidad, en sentido técnico, según la cual cualquier decisión, cualquier opción entre alternativas sería legítima. Más bien la intención del constituyente, [...], viene a ser precisamente la contraria. [...]. La Administración no cuenta con una autonomía de actuación completa. Su actuación está en principio determinada por las leyes, las cuales son las que efectúan, dentro de la Constitución, la selección de lo que en el concierto social debe ser calificado de interés general y confiado, en una u otra medida, a la gestión administrativa. Pero esta primera selección no agota la función del interés público. Con toda normalidad, las leyes encomiendan a la Administración una actuación determinada, y aun, dentro de ese ámbito de actuación, prescriben la necesidad de que la Administración tome en cuenta para adoptar ciertas medidas (excepciones al régimen común, adopción de medidas exorbitantes, etc.), un interés más cualificado".

En todo caso, tal y como afirmó el profesor Parejo Alfonso ${ }^{62}$, la cuestión estriba en que es imposible una definición a priori del interés público, pues el mismo ha de ser identificado en cada caso. Su definición es difícil, si no imposible, en términos generales. Resulta más sencilla desde una perspectiva negativa, es decir, mediante la identificación de actividades o medidas que

${ }^{61}$ Véase: GARcía De Enterría, Eduardo, Una nota sobre el interés general como concepto jurídico indeterminado, en REDA., 89 (1996), pp. 69-89.

${ }^{62}$ Véase: Parejo Alfonso, Luciano - -Jiménez Blanco, Antonio - Ortega Alvarez, Luis, Manual de Derecho administrativo (Barcelona, Ariel, 1988), I, p. 468. 
atentan contra el mismo. El contenido del interés público únicamente puede ser referido a valores, actuaciones y bienes existentes en cada momento histórico. Esta de la historicidad es, por cierto, otra característica del interés público, en la medida en que las comunidades políticas asumen en el tiempo diversos intereses o bienes colectivos. Las expresiones "interés público" e "interés general" son, por lo demás, versiones recientes de otra fórmula más depurada y precisa: la de bien común. El rechazo a las técnicas mediante las que antaño se buscó y delimitó el bien común (las técnicas previas al constitucionalismo, las propias del Antiguo Régimen) produjo el arrumbamiento de la expresión (no, lógicamente, de su esencia). El concepto de bien común vino entonces a ser formulado con palabras como interés general, interés público, interés social, utilidad pública, etc. En esta mutación terminológica confluyeron, junto a la apuntada, causas muy variadas: además del carácter económico que en ellas se percibe (interés y utilidad), el naciente socialismo jugó también en dicha mutación su papel.

En materia de ordenación farmacéutica y libertad -o no libertad- de establecimiento, es evidente que el interés general juega un papel decisivo a la hora de optar por uno u otro sistema, a la hora de precisar el régimen jurídico del elegido, en este lugar (Europa) y en este momento histórico.

b) ¿El hecho de que un Estado miembro imponga normas más rigurosas que las impuestas por otro Estado miembro en materia de protección de la salud pública, implica que estas normas sean incompatibles con las disposiciones del Tratado relativas a las libertades fundamentales?

La protección de la salud pública (garantizar un abastecimiento de medicamentos a la población seguro y de calidad) puede justificar restricciones a las libertades fundamentales garantizadas por el Tratado, entre las que figura la libertad de establecimiento (artículo 52, apartado 1 TFUE: "Las disposiciones del presente capítulo y las medidas adoptadas en virtud de las mismas no prejuzgarán la aplicabilidad de las disposiciones legales, reglamentarias y administrativas que prevean un régimen especial para los extranjeros y que estén justificadas por razones de orden público, seguridad y salud públicas"). Es necesario examinar si la normativa reseñada es adecuada para garantizar dicho objetivo.

La STJUE de 10 de febrero de 2009, "Comisión/Italia”, C-110/05, apartado 65, entiende que estas divergencias no son incompatibles con las disposiciones del Tratado relativas a las libertades fundamentales, y más en concreto, posibilita que algunos Estados no limiten el número de farmacias que puedan crearse en su territorio, mientras que otros países si lo hacen, y las someten a normas de planificación geográfica. En el Derecho de la Unión 
Europea, los establecimientos e infraestructuras sanitarias -incluidas las farmacias-, pueden ser objeto de planificación ${ }^{63}$.

De este modo se trata de evitar aglomeraciones en zonas urbanas y desabastecimiento en las restantes: "72. En tercer lugar, procede señalar que existen aglomeraciones que pueden ser percibidas por numerosos farmacéuticos como muy rentables y, en consecuencia, más atractivas, como las situadas en zonas urbanas. En cambio, otras partes del territorio nacional pueden considerarse menos atractivas, como las zonas rurales, geográficamente aisladas o que de alguna otra manera se hallan en una situación desventajosa./ 73. En estas circunstancias, no puede excluirse que, a falta de toda regulación, los farmacéuticos se concentrasen en las localidades consideradas atractivas, de manera que algunas otras localidades menos atractivas no dispondrian de un número suficiente de farmacéuticos para garantizar una atención farmacéutica segura $y$ de calidad"64.

Sin embargo, la realidad parece desterrar la consistencia de esta argumentación ${ }^{65}$. Y en todo caso la lentitud para la apertura de nuevas farmacias (por desidia de la Administración pública o por la demora en la sustanciación de los pleitos inherentes a cualquier convocatoria de cobertura de nuevos establecimientos), imposibilitan que el sistema establecido sea eficiente. Debo recordar que a los farmacéuticos establecidos les resulta muy rentable la interposición de recursos administrativos y judiciales, aun en el peor de los casos, es decir, cuando pierdan los pleitos, para imposibilitar -temporalment- el establecimiento de nuevos competidores.

Sin embargo, la Gran Sala entiende que de este modo se están evitando riesgos para la salud pública: "74. En cuarto lugar, es preciso recordar que,

${ }^{63}$ Véase: SSTJUE: 12 de julio de 2001, “Smits y Peerbooms”, C-157/99, apartados 76-80; 16 de mayo de 2006, "Watts", C-372/04, apartados 108-110. Establecen que "dicha planificación puede comprender una autorización previa para el establecimiento de nuevos prestadores de asistencia, cuando resulta indispensable para colmar posibles lagunas en el acceso a las prestaciones sanitarias y para evitar una duplicidad de estructuras, de forma que se garantice una asistencia sanitaria adaptada a las necesidades de la población, que cubra la totalidad del territorio y que tenga en cuenta las regiones geográficamente aisladas o que de alguna otra manera se hallan en una situación de desventaja".

${ }^{64}$ Véase: STJUE (Gran Sala) de 1 de junio de 2010, apartados: 72 y 73.

${ }^{65}$ Véase: Cervera Soto, Santiago, El modelo de atención farmacéutica en la legislación de Navarra, en Derecho y Salud, 8 (2001) 1, pp. 1 ss. Desde la entrada en vigor de la Ley 12/2000, de 16 de noviembre, de Atención Farmacéutica de Navarra, el módulo poblacional mínimo para la apertura de nuevas farmacias se ha situado en 700 habitantes, y las distancias mínimas en 150 metros. El número de farmacias rurales que ha cerrado (hasta 2005) es de ocho. Así consta en el informe emitido en diciembre de 2005, por el Instituto Austriaco de Sanidad, a petición de PGEU (Grupo Farmacéutico de la Unión Europea), titulado: La oficina de farmacia en Europa. Lecciones de la desregulación-estudio de casos concretos. 
cuando subsisten dudas sobre la existencia o el alcance de riesgos para la salud pública, el Estado miembro puede adoptar medidas de protección sin tener que esperar a que se demuestre plenamente la realidad de tales riesgos./ 75. En estas circunstancias, un Estado miembro puede considerar que existe un riesgo de escasez de farmacias en determinadas partes de su territorio y, por consiguiente, de falta de abastecimiento seguro y de calidad de medicamentos./ 76. En consecuencia, habida cuenta de este riesgo, un Estado miembro puede adoptar una normativa que establezca que sólo se pueda crear un a farmacia en relación con un determinado número de habitantes./ 77. En efecto, tal requisito puede canalizar la implantación de farmacias hacia las partes del territorio nacional en las que el acceso a la atención farmacéutica presente lagunas, puesto que, al impedir a los farmacéuticos establecerse en zonas en las que ya existe un numero suficiente de farmacias, les invita, asi, a instalarse en zonas en las que exista escasez de farmacias./ 78. De ello se desprende que el referido requisito es adecuado para distribuir las farmacias de manera equilibrada en el territorio nacional, garantizar asi a toda la población un acceso apropiado a la atención farmacéutica y, en consecuencia, aumentar la seguridad y calidad del abastecimiento de medicamentos a la población" ${ }^{66}$.

c) ¿Sería posible solucionar esta cuestión, si sólo se establece el requisito relativo a los módulos de población? Distancia mínima y módulos de población son medidas complementarias.

Entiende el TJUE ${ }^{67}$ que no sería posible solucionar esta cuestión, si sólo se establece el requisito relativo a los módulos de población, por que podría dar lugar a concentración de farmacias en el interior de una zona geográfica determinada, y por tanto, a una duplicidad de estructuras, mientras que en otras partes podrían sufrir falta de farmacias. Este es el sentido que tiene el requisito de distancia mínima entre los distintos operadores.

Además se señala que de este modo se atiende mejor la dispensación urgente de medicamentos y se da más cercanía física a las personas con movilidad reducida, de edad avanzada o gravemente enfermas.

Es decir, distancia mínima y módulos de población son medidas complementarias para la consecución del objetivo de un mejor servicio farmacéutico, distribuido de modo equilibrado en el territorio, garantizando a toda la población un acceso apropiado, seguro y de calidad.

Sin embargo, en España, es posible un mayor y mejor reparto del negocio de la dispensación de medicamentos, sin temor a la duplicidad de estructuras, ni a poner en peligro la calidad de la prestación ${ }^{68}$. Debemos tener en cuenta

${ }^{66}$ Véase: STJUE (Gran Sala) de 1 de junio de 2010, apartados: 74-78.

${ }^{67}$ Ibíd., apartados 79-84.

${ }^{68}$ Véase el informe emitido en diciembre de 2005, por el Instituto Austriaco de Sanidad, a petición de PGEU (Grupo Farmacéutico de la Unión Europea), titulado: La 
que el mayor precio de las nuevas especialidades farmacéuticas autorizadas en los últimos años, así como la actual coyuntura económica y los niveles presupuestarios establecidos para el gasto público sanitario y en concreto para la prestación farmacéutica, han motivado la adopción de una serie de medidas orientadas a la reducción de ese gasto. Además los márgenes de dispensación al público de especialidades farmacéuticas no sólo afectan al gasto sanitario público, sino que tienen una repercusión importante sobre el paciente que adquiere medicamentos no financiados por el Sistema Nacional de Salud.

Con respecto a la oficina de farmacia, durante los últimos años se ha producido un sensible y continuado incremento de sus ingresos, superior en todo caso tanto al nivel de crecimiento de la economía española en su conjunto, como al índice general de precios lo que ha hecho aconsejable promover un reajuste del margen vigente. Ello permite, a la vez una utilización más racional de los recursos destinados al sistema sanitario público para atender de forma eficaz los objetivos esenciales de la salud individual y colectiva.

d) ¿Se tiene presente la promoción o mejora de los farmacéuticos establecidos o que quieran establecerse?

La reserva de propiedad de las farmacias a favor de los farmacéuticos ha sido objeto de reiterada consideración tanto por la doctrina, como por la jurisprudencia. La independencia profesional frente a quienes no ostentan el título académico, puede favorecer la seguridad y calidad de la dispensación de medicamentos a la población. La Sentencia del Tribunal de Justicia de las Comunidades Europeas (Gran Sala) de 19 de mayo de 2009, así lo corrobora (apartado 59): "A este respecto, habida cuenta de la facultad reconocida a los Estados miembros para decidir el nivel de protección de la salud pública, procede admitir que éstospueden exigir que los medicamentos sean distribuidos por farmacéuticos que tengan una independencia profesional real. Asimismo, pueden adoptar medidas que permitan eliminar o reducir el riesgo de que se vulnere dicha independencia, dado que tal vulneración podria afectar al nivel de seguridad y calidad del abastecimiento de medicamentos a la población".

Esta cuestión que puede ser objeto de diversos pronunciamientos, no resuelve el interrogante que se plantea en este caso, es decir, ¿se tiene presenta la promoción o mejora de los farmacéuticos establecidos o que quieran establecerse? El TJUE entiende que sí, a tenor de los criterios establecidos

oficina de farmacia en Europa. Lecciones de la desregulación-estudio de casos concretos, p. 178: “[...], por término medio, una farmacia de España, tiene una facturación anual de cerca de 745.000 euros (datos para 2004), incluyendo medicamentos sin prescripción y productos farmacéuticos. La facturación media de la oficina de farmacia se ha duplicado en los últimos 10 años, siendo cinco veces mayor que en 1990". 
en la fase de selección, y que han sido objeto de consideración a lo largo de este trabajo ${ }^{69}$.

Sin embargo, los demandantes en el litigio resuelto el 1 de junio de 2010 y la plataforma para la libre apertura de farmacias sostienen lo contrario, puesto que lleva a algunos farmacéuticos a verse privados del acceso a la actividad profesional independiente (libre elección de profesión u oficio) ${ }^{70}$,

${ }^{69}$ Véase: STJUE (Gran Sala) de 1 de junio de 2010, apartado: “86. En efecto, de conformidad con el punto 7, letra b) del anexo de dicho Decreto, en caso de empate al aplicar el baremo de méritos en virtud del cual se selecciona a los titulares de las nuevas farmacias, las autorizaciones se otorgarán según un orden de prelación que da prioridad, tras las categorias de farmacéuticos que figuran en el referido punto 7, letra a), a los farmacéuticos que hayan sido titulares de oficinas de farmacia en zonas farmacéuticas o municipios de población inferior a 2.800 habitantes. 87. Habida cuenta de que las zonas geográficas cuya población es inferior a 2.800 habitantes son generalmente zonas consideradas por los farmacéuticos menos atractivas, dicho requisito para la concesión de una autorización pretende alentar a los farmacéuticos a establecerse en dichas zonas ante la perspectiva de ser recompensados ulteriormente con la concesión de otras autorizaciones de instalación de nuevas farmacias".

${ }^{70}$ Tras la Constitución española de 1978, va a ser el Tribunal Constitucional el que justifique la restricción de derechos fundamentales como la "Libre elección de profesión u oficio" (artículo 35.1 CE) o "Libertad de empresa" (artículo $38 \mathrm{CE}$ ), en aras del bien superior "Salud Pública", en la STC 83/1984, en base a las siguientes consideraciones: "El derecho constitucionalmente garantizado en el articulo 35.1 de la CE no es el derecho a desarrollar cualquier actividad, sino el de elegir libremente profesión u oficio, y en el articulo 38 no se reconoce el derecho a acometer cualquier empresa, sino sólo el de iniciar y sostener en libertad la actividad profesional, cuyo ejercicio está disciplinado por normas de muy distinto orden. La regulación de las distintas profesiones, oficio o actividades empresariales en concreto no es, por tanto, una regulación del ejercicio de los derechos constitucionalmente garantizados en los arts 35.1 o 38./ Lo anterior no significa que las regulaciones limitativas queden entregadas al arbitrio de los reglamentos, pues el principio general de libertad que la Constitución consagra (artículo 1.1) autoriza a los ciudadanos a llevar a cabo todas aquellas actividades que la ley no probiba, o cuyo ejercicio no se subordine a un requisito o condiciones determinadas, y el principio de legalidad (arts 93 y 103.1) impide que la Administración dicte normas sin la suficiente habilitación legal. En unos casos, bastarán para ello las cláusulas generales; en otros, en cambio, las normas reguladoras o limitativas deberán tener, en cuanto tales, rango legal, pero ello no por exigencia de los artículos 35.1 y 38 de la Constitución, sino en razón de otros artículos de la Constitución que configuran reservas especificas de Ley. En el caso de las profesiones tituladas, a las que se refiere el artículo 36 de la Constitución española, su simple existencia (esto es, el condicionamiento de determinadas actividades a la posesión de concretos titulos académicos) es impensable sin la existencia de una Ley que las discipline y regule su ejercicio. Esta reserva especifica es bien distinta de la general que se contiene en el artículo 53.1 de la Constitución y, en consecuencia, no puede oponerse aqui al legislador la necesidad de preservar ningún contenido esencial de derechos y libertades. La regulación del ejercicio profesional, en cuanto no choque con otros preceptos constitucionales, puede ser hecha por el legislador en los términos que tenga por conveniente”. Por tanto, habrá profesiones cuyas limitaciones vengan dadas 
mientras que los farmacéuticos establecidos en el mercado gozan de ventajas desproporcionadas.

En todo caso, la jurisprudencia del TJUE ha señalado de modo reiterado, que la libertad de establecimiento debe ponderarse en relación con los imperativos de protección de la salud pública que han sido señalados. Por tanto, la importancia de los objetivos perseguidos, puede justificar restricciones ${ }^{71}$.

La convocatoria periódica de concursos para la apertura de nuevas farmacias, o la no valoración de la experiencia profesional previamente acreditada para la obtención de una farmacia, así como la resolución de los empates en la normativa establecida al efecto (en este caso, el Decreto $\mathrm{N}^{\circ} 72 / 2001$, de 19 de julio, anexo, punto 4), estableciendo un orden de prelación que da prioridad a los farmacéuticos sin farmacia, pretende garantizar el acceso a más farmacéuticos al ejercicio profesional independiente.

e) ¿Es congruente la normativa enjuiciada? El TJUE, en esta sentencia, entiende que la normativa cuestionada es adecuada para alcanzar el objetivo de garantizar un abastecimiento de medicamentos a la población seguro y de calidad. Pero, ¿es congruente?. Sólo sería admisible la regulación cuestionada, si para alcanzar el objetivo propuesto, lo hace de forma congruente y sistemática.

Para analizar esta cuestión, es preciso tener en cuenta la Ley $N^{\circ} 16 / 1997$, y su desarrollo en el Decreto $\mathrm{N}^{\circ} 72 / 2001$, de 19 de julio, en lo relativo a las particularidades demográficas de determinadas zonas, distancias mínimas entre farmacias y el correcto acceso a la atención farmacéutica.

Respecto a la primera cuestión, entiende el Tribunal ${ }^{72}$, que la normativa nacional permite establecer medidas de ajuste para atenuar las consecuencias de la aplicación de la norma base en lo relativo a los 2.800 habitantes, con especial incidencia en las zonas rurales, turísticas o de montaña ${ }^{73}$.

Por el contrario, en zonas con una gran densidad demográfica, el requisito relativo a la distancia mínima entre farmacias, podría dar lugar a que no se garantizase un acceso apropiado a la atención farmacéutica en determinadas áreas geográficas de gran concentración demográfica ${ }^{74}$. La ley estatal, prevé dicho supuesto, permitiendo la posibilidad de autorizar distancias menores $^{75}$.

por meras cláusulas legales generales; otras, para su acceso o ejercicio requerirán de una ley especial; pero no por exigencias de los artículos 35.1 y 38 de la Constitución, sino en razón de otros artículos de ésta donde se imponen reservas de ley específicas.

${ }^{71}$ Véase: STJUE de 17 de julio de 1997, “Affish”, C-183/95, apartados 42 y 43.

${ }^{72}$ Véase: STJUE (Gran Sala) de 1 de junio de 2010, apartados 97 y 98.

${ }^{73}$ Véase: Ley 16/1997, de 25 de abril, artículo 2.3, párrafo segundo.

${ }^{74}$ Véase: STJUE (Gran Sala) de 1 de junio de 2010, apartado 99.

${ }^{75}$ Véase: Ley 16/1997, de 25 de abril, artículo 2.4. 
Serán los tribunales españoles los que deberán enjuiciar la correcta aplicación de las previsiones legales contempladas en la norma para los supuestos especiales reseñados. Por tanto, la normativa, a juicio del TJUE es adecuada para lograr el objetivo perseguido, es decir, es congruente ${ }^{76}$.

f) ¿Existen medidas menos restrictivas para lograr el objetivo propuesto? ¿Es muy severa la restricción a la libertad de establecimiento? Es necesario examinar si la restricción de la libertad de establecimiento, no va más allá de lo necesario para lograr el objetivo invocado.

Se señala por algunas de las partes, en especial, por la plataforma para la libre apertura de farmacias, que bastaría con establecer un "sistema de mínimos", que garantizase que hasta tanto no existiera el número mínimo de farmacias previamente determinada en cada zona geográfica (partido farmacéutico), no se autorizarían nuevas aperturas.

Sobre esta cuestión, remite el Alto Tribunal ${ }^{77}$ al margen de apreciación de que disponen los Estados miembros en materia de protección de la salud pública y lo justifica en base a criterios reproducidos en este trabajo con anterioridad. Su consecuencia más inmediata es la ubicación de nuevas aperturas en zonas desatendidas o carentes de farmacias, en las que el abastecimiento de medicamentos a la población es insuficiente, y en las que, por tanto, se autoriza la instalación de farmacias. Además, el Reino de España, puede legítimamente organizar el sistema de distribución territorial a escala regional, aunque esta situación podría perjudicar el objetivo nacional, de canalizar a los farmacéuticos hacia las zonas desprovistas de farmacias sin importar la región de que se trate. Por todo ello entiende que no es muy severa la restricción impuesta.

\section{SEgundo PROBlema QUE aborda LA SENTENCIA: PONDERACIÓN} ADICIONAL DE LOS MÉRITOS PROFESIONALES REFERIDOS AL

EJERCICIO EN UN ÁMBITO TERRITORIAL DETERMINADO

El Tribunal Superior de Justicia de Asturias, planteaba en la cuestión prejudicial varias consideraciones relativas a los criterios de selección de los titulares de nuevas farmacias. Lo relativo al acceso, promoción o mejora de los farmacéuticos ya ha sido abordado en un epígrafe anterior. Pero queda pendiente una cuestión muy relevante, que es la relativa a la ponderación de los méritos profesionales referidos al ejercicio profesional obtenidos en

${ }^{76}$ Véase: STJUE (Gran Sala) de 1 de junio de 2010, apartados 102 y 103.

${ }^{77}$ Véase: STJUE (Gran Sala) de 1 de junio de 2010, apartados 106-108. 
el ámbito del Principado de Asturias, si se computan con un determinado incremento. En la demanda que nos ocupa, un $20 \%$.

El Tribunal de Justicia de la Unión Europea debe dilucidar, si el artículo 49 TFUE se pone a los criterios recogidos en los puntos 6 y 7 , letra c), del referido anexo, del Decreto $\mathrm{N}^{\circ} 72 / 2001$, de 19 de julio, teniendo en cuenta que el precepto comunitario exige que los criterios aplicables en el marco de un régimen de autorización administrativa no sean discriminatorios (de modo directo, en base a la nacionalidad, o de modo indirecto a través de cualquier forma de discriminación encubierta que, aplicando otros criterios de diferenciación, conduzca de hecho al mismo resultado $)^{78}$. Se trata de una clara concreción del derecho al trato nacional. Es evidente, que ambos criterios privilegian en el proceso de selección a los farmacéuticos que han ejercido su actividad en una parte de España (Asturias), y determina que no es admisible. Resulta un hecho cierto, que dicho requisito es más fácil de cumplir, por los farmacéuticos nacionales, quienes ejercen con mayor frecuencia su actividad económica en el territorio de su país (Comunidad Autónoma), que por los farmacéuticos de otros Estados miembros ${ }^{79}$.

A juicio del TJUE no puede acogerse tal alegación, "puesto que el artículo 1 , apartados 1 y 2 , de la Directiva $N^{\circ} 85 / 432$ y el artículo 45 , apartado 2, letras e) y g), de la Directiva $N^{\circ} 2005 / 36$ exigen que los titulares de un título profesional de formación universitaria de farmacia sean habilitados para el acceso a las actividades de preparación, control, almacenamiento y distribución de los medicamentos en las farmacias abiertas al público, así como a las actividades de difusión de información y asesoramiento sobre medicamentos. En estas circunstancias no pueden invocarse los requisitos mencionados en el apartado anterior para justificar una desigualdad de trato como la controvertida en los asuntos principales" ${ }^{\prime 0}$.

${ }^{78}$ Véase: SSTJUE: 26 de junio de 2001, “Comisión/Italia”, C-212/99, apartado 24, y de 19 de marzo de 2002, "Comisión/Italia”, C-224/00, apartado 15.

${ }^{79}$ Véase: STJUE (Gran Sala) de 1 de junio de 2010, apartado 123: "No obstante, la Consejería de Salud y Servicios Sanitarios y el Principado de Asturias sostienen que la necesidad de mantener el nivel de calidad de la atención farmacéutica puede justificar la diferencia de trato, habida cuenta de que dicho nivel se vería reducido si los farmacéuticos que se establecen no pudiesen prestar inmediatamente la atención farmacéutica. Pues bien, consideran que tal posibilidad inmediata de actuar de los farmacéuticos exige, en particular, que conozcan los programas de salud previstos por la Administración regional así como el funcionamiento de las farmacias de esa región".

${ }^{80}$ Véase: STJUE (Gran Sala) de 1 de junio de 2010, apartado 124. 


\section{FINAL}

Los riesgos para la salud pública y el equilibrio financiero de los sistemas de seguridad social ${ }^{81}$, permiten a los Estados de la Unión Europea imponer serias restricciones a la comercialización de medicamentos. En los últimos años se han planteado dos interrogantes fundamentales.

Primero, si la reserva de su venta al por menor, en principio, exclusivamente a los farmacéuticos, debido a las garantías que éstos deben presentar y a la información que deben ser capaces de proporcionar al consumidor, vulnera o no el derecho comunitario. La Sentencia del Tribunal de Justicia de las Comunidades Europeas (Gran Sala) de 19 de mayo de 2009, entiende que no, y por tanto reserva la titularidad y la explotación de las farmacias exclusivamente a quienes tengan la condición de farmacéutico, sin que exista vulneración del derecho de establecimiento, ni de la libre circulación de capitales.

El segundo interrogante, cuestionaba la existencia de un modelo que limita el número de autorizaciones (ordenación farmacéutica), y que por tanto puede vulnerar la libertad de establecimiento en base a criterios demográficos o geográficos, o que diseña modalidades de adjudicación con una baremación de méritos cuestionable, en base al régimen jurídico de la Unión europea. La Sentencia del Tribunal de Justicia (Gran Sala) de 1 de junio de 2010, se ha pronunciado sobre el particular, resolviendo las dos cuestiones prejudiciales planteadas por el Tribunal Superior de Justicia de Asturias.

Respecto de la primera, ha determinado que "no puede considerarse que la normativa controvertida en los litigios principales vaya más allá de lo necesario para lograr el objetivo perseguido" 82 , y por tanto concluye declarando en el fallo, que "el articulo 49 TFUE debe interpretarse en el sentido de que no se opone, en principio, a una normativa nacional, como la controvertida, que impone limites a la concesión de autorizaciones de establecimiento de nuevas farmacias", en virtud de los módulos poblacionales y distancias mínimas expuestos. Esta es la primera conclusión que declara el fallo de la sentencia.

En relación con la segunda cuestión prejudicial planteada, el Tribunal falla que "el artículo 49 TFUE, en relación con el artículo 1, apartados 1 y 2,

${ }^{81}$ Véase: Ezquerra Huerva, Antonio, Acerca del blindaje comunitario de la reserva de la propiedad de las oficinas de farmacia a favor de los farmacéuticos. Consideraciones al hilo de las sentencias del Tribunal de Justicia de las Comunidades Europeas de 19 de mayo de 2009 (asuntos acumulados C-171/07 y C-172/07, y asunto C-531/06), en Revista de Administración Pública, 180 (2009), pp. 268-271: "La desafortunada vinculación entre el régimen de titularidad de las farmacias y el coste público de la prestación farmacéutica".

${ }^{82}$ Véase: STJUE (Gran Sala) de 1 de junio de 2010, apartado 112. 
de la Directiva $N^{\circ}$ 85/432/CEE del Consejo, de 16 de septiembre de 1985, relativa a la coordinación de las disposiciones legales, reglamentarias y administrativas para ciertas actividades farmacéuticas, y el articulo 45, apartado 2, letras e) y g), de la Directiva $N^{\circ}$ 2005/36/CE del Parlamento Europeo y del Consejo, de 7 de septiembre de 2005, relativa al reconocimiento de cualificaciones profesionales, debe interpretarse en el sentido de que se opone a criterios (desigualdad de trato, privilegiar en el proceso de selección a los farmacéuticos autóctonos) como los recogidos en lospuntos $6 y$ 7, letra c), del anexo del Decreto $N^{\circ} 72 / 2001$, de 19 de julio, regulador de las oficinas de farmacia y botiquines en el Principado de Asturias, en virtud de los cuales se selecciona a los titulares de nuevas farmacias".

De este modo se cierra el círculo abierto en el año 2006 por la Comisión Europea. Los Estados de la Unión, en el ámbito de la salud pública, disponen de una esfera competencial infranqueable para las instituciones comunitarias, y por tanto, pueden ordenar y organizar sus servicios sanitarios -ordenación farmacéutica-, de la forma que estimen más conveniente. Ningún acto de aplicación de las libertades fundamentales establece normas de acceso a las actividades del ámbito farmacéutico destinadas a establecer las condiciones en las que se pueden crear nuevas farmacias en el territorio de los estados miembros. De este modo se permite la existencia de un régimen de liberalización o de normas más o menos restrictivas en los distintos países.

La distribución competencial española entre el Estado y las Comunidades Autónomas, permite a éstas disponer la regulación del acceso, explotación y transmisión de unos establecimientos -las farmacias- sanitarios y mercantiles. En todo caso, deben respetar el Derecho de la Unión imposibilitando la discriminación por razón de nacionalidad o por condicionantes que tienen que ver con el desarrollo del ejercicio profesional en una determinada zona geográfica, y haciendo posible el acceso y la promoción o mejora de los farmacéuticos titulados.

Desde el punto de vista formal, la argumentación es impecable. Desde el punto de vista material, es posible cuestionar un modelo seguro y fiable, en la medida en que las restricciones impuestas casan mal con el imparable proceso de liberalización que afecta a todos los ámbitos de la vida de los ciudadanos europeos.

El modelo español puede modificarse. A corto plazo es difícil (la presión corporativa es extraordinaria), pero no existen problemas de fondo que imposibiliten un mayor y mejor acceso de los ciudadanos a esta prestación. El modelo comunitario, sustentado en el principio de subsidiariedad, concluye remitiendo a los operadores nacionales (ejecutivo, legislativo y judicial) la responsabilidad de una actividad, que de una u otra forma, seguirá estando 
en el punto de mira ${ }^{83}$. El legislador, contando con los actores principales, tiene la última palabra.

[Recibido el 27 de septiembre y aprobado el 8 de octubre de 2010].

\section{BiBLIOGRAFÍA}

\section{Literatura}

Barranco Vela, Rafael (director) - Bombillar Sáenz, Francisco Miguel (coordinador), El acceso al medicamento (Granada, Comares, 2010).

Beladiez Rojo, M., La vinculación de la Administración al Derecho, en Revista de Administración Pública, 153 (2000).

Carrasco Durán, M., Las competencias en la proposición de reforma del Estatuto de Autonomia para Andalucia: entre la norma y la realidad, en Revista Vasca de Administración Pública, 76 (2006).

Cervera Soto, Santiago, El modelo de atención farmacéutica en la legislación de $\mathrm{Na}$ varra, en Derecho y Salud, 8 (2001) 1.

Consejo General de Colegios Oficiales de Farmacéuticos, Informe: Modelos de farmacia en la Unión Europea, (diciembre de 2007).

Ezluerra Huerva, Antonio, Acerca del blindaje comunitario de la reserva de la propiedad de las oficinas de farmacia a favor de los farmacéuticos. Consideraciones al hilo de las sentencias del Tribunal de Justicia de las Comunidades Europeas de 19 de mayo de 2009 (asuntos acumulados C-171/07 y C-172/07, y asunto C-531/06), en Revista de Administración Pública, 180 (2009).

GARCÍA De ENTERRÍA, Eduardo, Una nota sobre el interés general como concepto jurídico indeterminado, en REDA., 89 (1996).

Gimeno Feliu, J. Ma., Sistema económico y derecho a la libertad de empresa versus reservas al sector público de actividades económicas, en Revista de Administración Pública, 135 (1994).

Instituto Austriaco de Sanidad, Informe emitido en diciembre de 2005 a petición de PGEU (Grupo Farmacéutico de la Unión Europea), titulado: La oficina de farmacia en Europa. Lecciones de la desregulación-estudio de casos concretos.

Instituto Austriaco de Sanidad, a petición de PGEU (Grupo Farmacéutico de la Unión Europea), titulado: La oficina de farmacia en Europa. Lecciones de la desregulaciónestudio de casos concretos.

\footnotetext{
${ }^{83}$ Véase: ORdoñez Solís, David, La regulación española de las oficinas de farmacia en el contexto del mercado único a la luz de la jurisprudencia europea, en Gaceta Jurídica de la Unión Europea y de la Competencia, 10 (2009), p. 30: "En suma y aun cuando los vientos de liberalización de y desregulación no soplen ahora con el brío de antes del inicio de la crisis económica, los intereses de unos y de otros, de gran trascendencia económica y social, harán que el sector farmacéutico y el régimen de las oficinas de farmacia esté en el punto de mira. Ahora bien, dentro del marco comunitario europeo y respetando los límites del Derecho de la Unión, corresponde a las autoridades nacionales -en España al legislador estatal y a los legisladores autonómicos- establecer finalmente el modelo de oficina de farmacia que nuestra sociedad requiere".
} 
Martín Mateo, Ramón, La sustantividad del derecho administrativo, en Revista de Administración Pública, 53, (1967).

MuÑoz Machado, S., La formación y crisis de los servicios sanitarios públicos (Madrid, Alianza Editorial, 1995).

Nieto, Alejandro, La Administración sirve con objetividad los intereses generales, en Estudios sobre la Constitución Española (Homenaje al profesor Eduardo García de Enterria) (Madrid, Cívitas, 1991), III.

Nieto, Alejandro, La Ley alemana de Farmacia de 28 de agosto de 1960, en Revista de

OrdoñEz Solís, David, La regulación española de las oficinas de farmacia en el contexto del mercado único a la luz de la jurisprudencia europea", en Gaceta Jurídica de la Unión Europea y de la Competencia, 10 (2009).

Parejo Alfonso, Luciano - -Jiménez Blanco, Antonio - Ortega Alvarez, Luis, Manual de Derecho administrativo (Barcelona, Ariel, 1988), I.

Pemán Gavín, J., Derecho a la saludy Administración sanitaria, (Publicaciones del Real Colegio de España, Bolonia, 1989).

Pérez GÁlvez, Juan Francisco, Reconocimiento del titulo de farmacéutico especialista en la Unión Europea: farmacia hospitalaria Comentario a la STJCE (Sala Segunda) de 8 de mayo de 2008, en Noticias de la Unión Europea, 306 (2010).

Pérez Gálvez, Juan Francisco, Transmisibilidad, caducidad y cotitularidad de las farmacias (Comentario a la STC 109/2003, de 5 de junio), en Revista Jurídica de Navarra, 36 (2003).

RazQuin Lizarraga, J. A., La competencia de las Comunidades autónomas y de la Comunidad Foral de Navarra sobre ordenación farmacéutica, en Revista Jurídica de Navarra, 20 (1995).

RAzQuin LizarRaga, José Antonio, La reserva de la propiedad y la titulariza de las oficinas de farmacia a los farmacéuticos no es contraria al Derecho comunitario europeo, en Actualidad Jurídica Aranzadi, 777 (2009).

Sala Arguer, J. M. - Villar Rojas, F., Análisis de la cooperación en un sector determinado: la sanidad pública, en Derecho y Salud, 10 (2002) 1.

Tribunal de Defensa de la Competencia, La competencia en España: balance $y$ nuevas propuestas, (Madrid, 1995).

Villalba PÉrez, Francisca, Situación jurídica actual de las oficinas de farmacia en España, en Noticias de la Unión Europea, 251 (2005).

Normas

Carta Social Europea promulgada por el Consejo de Europa, en Turín, en 1961.

Constitución española de 1978.

Constitución italiana de 1947.

Constitución portuguesa de 1976.

Declaración universal de los derecho del hombre, aprobada por la ONU el 10 de diciembre de 1948.

Decreto $\mathrm{N}^{\circ} 72 / 2001$, de 19 de julio, regulador de las oficinas de farmacia y botiquines en el Principado de Asturias.

Directiva N ${ }^{\circ}$ 2005/36/CE del Parlamento Europeo y del Consejo, de 7 de septiembre de 2005.

Ley $\mathrm{N}^{\circ} 16 / 2003$, de 28 de mayo, de cohesión y calidad del Sistema Nacional de Salud.

Ley $\mathrm{N}^{\circ} 29 / 2006$, de 26 de julio, sobre garantías y uso racional de los medicamentos y productos sanitarios (BOE. de 27 de julio de 2006, núm. 178). 
Martín Rebollo, L., Leyes administrativas (Pamplona, Aranzadi, 2010).

Pacto Internacional de derechos económicos, sociales y culturales de 19 de diciembre de 1966.

"Preámbulo" de la Constitución de la Organización Mundial de la Salud, de 22 de julio de 1946.

"Preámbulo" de la Constitución francesa de 1946.

Real Decreto $N^{\circ} 1093 / 2010$, de 3 de septiembre, por el que se aprueba el conjunto mínimo de datos de los informes clínicos en el Sistema Nacional de Salud (BOE. de 16 de septiembre, núm. 225).

Real Decreto $\mathrm{N}^{\circ} 1093 / 2010$, de 3 de septiembre, por el que se aprueba el conjunto mínimo de datos de los informes clínicos en el Sistema Nacional de Salud (BOE. de 16 de septiembre, núm. 225).

Tratado de 13 de diciembre de 2007 [Tratado sobre el Funcionamiento de la Unión Europea. Para la redacción de este trabajo, utilizo la versión consolidada subsiguiente al "Tratado de Lisboa", de 13 de diciembre 2007) (DOUE núm. 83, de 30 de marzo 2010)]. 